\title{
Competitive Markets, Collective Decisions and Group Formation
}

Gersbach, Hans; Haller, Hans Hermann

Publication date:

2002

Document version

Early version, also known as pre-print

Citation for published version (APA):

Gersbach, H., \& Haller, H. H. (2002). Competitive Markets, Collective Decisions and Group Formation. Department of Economics, University of Copenhagen. 


\section{DISCUSSION PAPERS Department of Economics University of Copenhagen}

$$
02-11
$$

Competitive Markets, Collective Decisions and Group Formation

Hans Gersbach

Hans Haller

Studiestræde 6, DK-1455 Copenhagen K., Denmark

Tel. +45 35323082 - Fax +45 35323000

http://www.econ.ku.dk 


\title{
Competitive Markets, Collective Decisions and Group Formation*
}

\author{
Hans Gersbach ${ }^{\dagger}$ and Hans Haller ${ }^{\ddagger}$
}

October 21, 2002

\begin{abstract}
We consider a general equilibrium model where households operating in a competitive market environment can have several members and make efficient collective consumption decisions. Individuals have the option to leave the household and make it on their own or join another household. We study the effect of these outside options on household formation, household stability, equilibrium existence, and equilibrium efficiency.
\end{abstract}

JEL Classification: D10, D50, D62, Dr0

Key Words: Household Behavior; Household Formation; Collective Decision Making; General Equilibrium

CORRESPONDING AUTHOR: HANS HALLER

PHONE: ++540 231-7591; FAX: ++540 231-5097

${ }^{*}$ We are grateful to James Dow and two referees for valuable suggestions and to Clive Bell, Volker Böhm, Martin Hellwig, Benny Moldovanu, Till Requate, Rasched Zamni, participants of the 2000 World Congress of the Econometric Society in Seattle, WA, and seminar participants in Basel, Berlin, Bielefeld, Bonn and Heidelberg for helpful comments.

$\dagger$ Alfred-Weber-Institut, University of Heidelberg, Grabengasse 14, D-69117 Heidelberg, Germany. email: gersbach@uni-hd.de.

Department of Economics, Virginia Polytechnic Institute and State University, Blacksburg, VA 24061-0316, USA.email: haller@vt.edu. 


\section{Introduction}

Concurrent interest in the formation, composition, stability, and decision making of households or, more generally, socio-economic groups requires a formal framework that incorporates the allocation of commodities to consumers and of people to households. We are going to analyze a general equilibrium model with multi-member households where such a dual allocation is brought about by three interacting mechanisms, each operating at a particular level of aggregation: Individual decisions are made to join or leave households. Collective decisions within households determine the consumption plans of household members. Competitive exchange across households achieves a feasible allocation of resources. Clearly, the three mechanisms interact. The household structure (that is the partition of the population into households) and the attractiveness of alternative households affect market prices and the allocation of resources among consumers. Conversely, market prices and the implied market opportunities influence the formation and stability of households. An economic theory of pure exchange among households ought to account for these interdependencies.

When dealing with household formation, one of the most critical modeling assumptions is how much choice between households an individual has. Here we consider a finite pure exchange economy with variable household structure and focus on two types of outside options available to household members. We first develop the concept of a competitive equilibrium with free exit (CEFE) where household members have one type of outside option, the "exit option" (EO): an individual may decide to leave its household and become single if this is to its advantage. Then we develop the concept of competitive equilibrium with free household formation (CEFH) which adds a second type of outside option, the "joining option" (JO): an individual may decide to leave its household and get accepted by another household or individual if this benefits all members of the resulting enlarged household.

The choice of threat points in households has been examined in a number of papers surveyed in Bourguignon and Chiappori (1994). This literature suggests that it is difficult to identify threat points empirically. Therefore, in our theoretical analysis, we start with the exit option as the narrowest 
view advanced in the literature on how individuals behave in households. ${ }^{1}$ Then we are broadening the set of outside options. We focus on efficiency and existence of CEFE and CEFH and on which CEFE are eliminated by adding more outside options.

Our approach follows the seminal contribution of Becker (1973) who has demonstrated that an inquiry into the determinants of and connections between sociological and economic choices can be very productive. We use a different model and address different questions. For instance, householdspecific externalities play an important role in our approach. In contrast, Becker's model avoids consumption externalities in a unique way, by introducing a "household good", the sole explicit consumption good which is nontradable, yet perfectly divisible within each household and does not cause any consumption externalities.

Our investigation of interacting allocation and decision mechanisms begins with Gersbach and Haller (2001) where we follow Haller (2000) and incorporate the collective rationality concept of Chiappori (1988a, 1992) into a general equilibrium framework. There we perform welfare analysis with a variable household structure, but no outside options. ${ }^{2}$ An allocation consists of a household structure and an allocation of commodities to individual consumers. A competitive equilibrium is defined accordingly. A household resides in a competitive market environment and makes efficient collective consumption decisions for its members. This setting has allowed us to study the interaction between two allocation mechanisms: collective decisions and competitive markets. This basic model will be amended in the present paper, introducing the two types of outside options, EO and JO, which constitute elements of a third allocation mechanism, the individual choice of household

\footnotetext{
${ }^{1}$ Chiappori, Fortin, and Lacroix (2002) study the effect of a "divorce laws index" on intra-household decisions. This index measures how favorable are state divorce law provisions to women and ranges between 1 and 4 in the sample, with a mean of 2.48 and a standard error of 0.88 . It can be viewed as a rough proxy for the value of the exit option available to women. Chiappori et al. use 1988 PSID data of 1618 US households where both spouses have positive hours of work and are between 30 and 60 years old. They estimate that a one point increase in the divorce laws index induces husbands to transfer an additional $\$ 4,310$ of nonlabor income to their wives. This suggests a considerable impact of the exit option on the intra-household decision process, given that the average nonlabor income per household was approximately $\$ 8,000$.

${ }^{2}$ Corresponding equilibrium existence results can be found in Gersbach and Haller (1999).
} 
membership. Our conclusions are three-fold.

First, we establish a neutrality theorem which asserts that in the absence of externalities, the set of CEFE is identical to the set of CEFH and equal to the set of (traditional) competitive equilibria when all individuals act and trade individually. Therefore, if group or household formation does not create any group or consumption externalities, individuals remain powerless in the sense that every individual can fare no better and no worse as a member of a multi-member household than as an individual market participant. The exit threat is sufficient for this to hold and adding more outside options affects neither equilibrium existence nor equilibrium welfare under these particular circumstances.

Second, suppose that more outside options, say addition of JO, eliminate some but not all competitive equilibria with free exit. One might conjecture that more stringent equilibrium conditions make the surviving equilibria "stronger" or "better", having passed more tests than the eliminated ones. It turns out that this conclusion is premature if "better" means "Paretosuperior": A surviving equilibrium can be weakly Pareto-dominated by an eliminated one. This kind of result suggests that the availability and awareness of more outside options can be socially harmful. It can destabilize households and, therefore, the household structure. However, the availability and people's awareness of more outside options need not always be socially harmful. For instance, we obtain that in the case of one good and a unique optimal household structure, adding more outside options (of the first or second type) eliminates only Pareto-inefficient competitive equilibria, if any. Thus the welfare comparison, in the sense of Pareto, of competitive equilibria with free exit which are also competitive equilibria with free household formation and those which are not, can go either way.

Third, we establish existence of non-trivial CEFE. We also find that the additional outside option, JO, can eliminate all competitive equilibria with free exit. Whereas there exists a competitive equilibrium with free exit under standard assumptions, there need not exist a competitive equilibrium with free household formation under the same assumptions. Still, competitive equilibria with free household formation exist in many instances. One example is the case of one private good and a unique optimal household structure. Another example is the case of one private good and group externalities such that household formation can be reduced to a two-sided matching problem. 
But we also provide a counter-example, Example 6, with two private goods and household formation reducible to a two-sided matching problem. In Example 6, stable matchings and market clearing cannot be achieved simultaneously. This kind of market failure is notably absent from the vast majority of the matching literature where markets are inactive and relative prices are irrelevant, simply because there exits at most one tradable commodity.

Our model is related to the club literature and the literatures on hedonic coalitions, matching, assignment games, and multilateral bargaining. The novel approach to club theory taken by Ellickson et al. $(1999,2001)$ resembles ours in that it also deals with the allocation of individuals to groups (clubs, households) and the allocation of commodities to individuals. In our model, only the household at large is subject to a budget constraint and not necessarily each member. In contrast, club theory assumes that every club member is subject to an individual budget constraint. Both in household and in club models, individuals (indirectly or directly) participate in anonymous and competitive global markets and consider themselves exposed to market conditions on which they have no influence. One of the distinguishing features of the collective rationality assumption on households is that individuals do enjoy influence at the local or household level while they are without influence in the global market place. This important feature is missing in the existing club models. The precise relationship of our model to the club literature has been discussed in detail in the introduction and subsection 5.3 of Gersbach and Haller (2001).

We would further like to stress that Example 6 puts the traditional literature on matching into perspective. Namely, most of the work on hedonic coalitions [e.g. Greenberg (1978), Bogomolnaia and Jackson (2002), Banerjee et al. (2001)], matching [e.g. Gale and Shapley (1962), Alkan (1988), Roth and Sotomayor (1990)], assignment games [e.g. Shapley and Shubik (1972), Roth and Sotomayor (1990)], and multilateral bargaining [e.g. Rochford (1984), Crawford and Rochford (1986), Bennett (1988, 1997)] focuses on group formation and lacks competitive markets for commodities. Consequently, this literature fails to observe that in general, stable matchings and market clearing cannot be achieved simultaneously. ${ }^{3}$

\footnotetext{
${ }^{3}$ A noteworthy exception are Drèze and Greenberg (1980) who combine the concepts of individual stability and price equilibrium, but confine the analysis of their most comprehensive model to an instructive example.
} 
The paper is organized as follows: In the next section, we introduce the model. In section 3, we define and discuss the equilibrium concepts. Welfare properties of $\mathrm{CEFE}$ and $\mathrm{CEFH}$ are studied in section 4 . Existence issues are addressed in sections 5 and 6 . We conclude with section 7 where we elaborate on testability, efficient versus inefficient household decisions, and future extensions. Lenghtier proofs are collected in an appendix, section 8 .

\section{Consumer Characteristics and Allocations}

In this section, we describe the basic structure of the model: consumers, household structures, commodities, endowments, allocations, and preferences.

Consumers and Household Structures. We consider a finite population of consumers, represented by a set $I=\{1, \ldots, n\}$. A generic consumer is denoted $i$ or $j$. The population $I$ is partitioned into households ${ }^{4}$, i.e. there exists a partition $P$ of $I$ into non-empty subsets. We call any such partition $P$ a household structure in $I$. A generic household is denoted $h$ or $g$. Relative to $P$, we use the following terminology regarding $i \in I$ and $h \subseteq I$, $h \neq \emptyset$ :

"household $h$ exists" or "household $h$ is formed" $\quad$ iff $h \in P$;

" $i$ belongs to $h$ " or "individual $i$ is a member of household $h$ " iff $i \in h$.

If $P$ consists of $H$ households, we frequently label them $h=1, \ldots, H$, provided this causes no confusion. We treat the household structure as an object of endogenous choice. Households are endogenously formed so that some household structure $P$ is ultimately realized. Consequently, our consumer allocation space is $\mathcal{P}$, the set of all household structures in $I$.

Commodities. There exists a finite number $\ell \geq 1$ of commodities. Thus the commodity space is $\mathbb{R}^{\ell}$. Each commodity is formally treated as a private good, possibly with externalities in consumption. Consumer $i \in I$ has consumption set $X_{i}=\mathbb{R}_{+}^{\ell}$ so that the commodity allocation space is $\mathcal{X} \equiv \prod_{j \in I} X_{j}$. Generic elements of $\mathcal{X}$ are denoted $\mathbf{x}=\left(x_{i}\right), \mathbf{y}=\left(y_{i}\right)$. Com-

\footnotetext{
${ }^{4}$ While we stick to the suggestive term "household", a broader interpretation as socioeconomic group or simply group would be quite appropriate in many instances, in particular since as a rule we do not impose any restrictions on household or group size, respectively.
} 
modities are denoted by superscripts $k=1, \ldots, \ell$. For a potential household $h \subseteq I, h \neq \emptyset$, set $\mathcal{X}_{h}=\prod_{i \in h} X_{i}$, the consumption set for household $h$. $\mathcal{X}_{h}$ has generic elements $\mathbf{x}_{\mathbf{h}}=\left(x_{i}\right)_{i \in h}$. If $\mathbf{x}=\left(x_{i}\right)_{i \in I} \in \mathcal{X}$ is a commodity allocation, then consumption for household $h$ is the restriction of $\mathbf{x}=\left(x_{i}\right)_{i \in I}$ to $h$, $\mathbf{x}_{\mathbf{h}}=\left(x_{i}\right)_{i \in h}$.

Endowments. For a potential household $h \subseteq I, h \neq \emptyset$, its endowment is a commodity bundle $\omega_{h} \in \mathbb{R}^{\ell}$ given by the sum of the endowments of all participating individuals: $\omega_{h}=\sum_{i \in h} \omega_{\{i\}}$. The social endowment is given by

$$
\omega_{S} \equiv \sum_{h \in P} \omega_{h}
$$

Note that the social endowment is independent of the household structure, $\omega_{S}=\sum_{i \in I} \omega_{\{i\}}$.

Allocations. An allocation is a pair $(\mathbf{x} ; P) \in \mathcal{X} \times \mathcal{P}$ specifying the consumption bundle and household membership of each consumer. We call an allocation $(\mathbf{x} ; P) \in \mathcal{X} \times \mathcal{P}$ feasible, if

$$
\sum_{i \in I} x_{i}=\omega_{S}
$$

After the specification of individual preferences, by means of utility representations, an allocation determines the welfare of each and every member of society.

Consumer Preferences. In principle, a consumer might have preferences on the allocation space $\mathcal{X} \times \mathcal{P}$ and care about each and every detail of an allocation. For individual $i \in I$, we assume that $i$ has preferences on $\mathcal{X} \times \mathcal{P}$ represented by a utility function $U_{i}: \mathcal{X} \times \mathcal{P} \longrightarrow \mathbb{R}$.

In the following, we shall make the general assumption that an individual does not care about the features of an allocation beyond the boundaries of his own household. If a particular household structure is given, he is indifferent about the affiliation and consumption of individuals not belonging to his own household. Condition HSP is a formal expression of this assumption, with a slight abuse of notation.

(HSP) Household-Specific Preferences:

$$
U_{i}(\mathbf{x} ; P)=U_{i}\left(\mathbf{x}_{\mathbf{h}} ; h\right) \text { for } i \in h, h \in P,(\mathbf{x} ; P) \in \mathcal{X} \times \mathcal{P} .
$$


The general assumption HSP is justifiable on the grounds that we want to design a model where multi-member households play a significant allocative role. HSP still admits a lot of flexibility. For example, it permits various kinds of consumption externalities within households. Suitable externalities may prevent the formation of certain households, even though we are not explicitly restricting household size. In the sequel, we shall in particular exploit the occurrence of pure group externalities that depend solely on the persons belonging to a household. Pure group externalities can capture all aspects of the benefits of human beings living together. They can represent, for instance, the emotional benefit from living together with other persons in the same household or the opportunity for receiving advice. To formulate the latter externalities, define $\mathcal{H}_{i} \equiv\{h \subseteq I \mid i \in h\}$ for $i \in I$. $\mathcal{H}_{i}$ is the set of potential households of which $i$ would be a member.

(PGE) Pure Group Externalities: For each consumer $i$, there exist functions $U_{i}^{c}: X_{i} \rightarrow \mathbb{R}$ and $U_{i}^{g}: \mathcal{H}_{i} \rightarrow \mathbb{R}$ such that $U_{i}\left(\mathbf{x}_{\mathbf{h}} ; h\right)=U_{i}^{c}\left(x_{i}\right)+U_{i}^{g}(h)$ for $\mathbf{x}_{\mathbf{h}} \in \mathcal{X}_{h}, h \in \mathcal{H}_{i}$.

PGE assumes that one can additively separate the pure consumption effect $U_{i}^{c}\left(x_{i}\right)$ from the pure group effect $U_{i}^{g}(h)$. A very special case is the absence of externalities, corresponding to $U_{i}^{g} \equiv 0$. At the other extreme lies the purely hedonic case, with $U_{i}^{c} \equiv 0$ or $\ell=0$, studied by Banerjee et al. (2001) and Bogomolnaia and Jackson (2002).

All of our examples with the exception of Example 6 feature pure group externalities. But one should emphasize that despite their prominent role, our analysis is not confined to the case of pure group externalities. See in particular Propositions 3, 4, and 6.

\section{The Equilibrium Concepts}

Among the several conceivable ways to formulate an equilibrium state of a model with variable household structure, we define an equilibrium of commodities and consumers as a price sytem together with a household structure and a feasible resource allocation such that:

- a household chooses an efficient consumption schedule for its members, subject to the household budget constraint; 
- markets clear;

- no individual has an incentive to leave a household and to participate as an individual in the market at the going prices.

These three conditions define a competitive equilibrium with free exit. We shall further allow for a second outside option:

- no individual can leave a household and get accepted by another household by proposing a feasible allocation for the enlarged household which makes everybody in this newly formed household better off at the going prices.

Adding the second option defines a competitive equilibrium with free household formation.

\subsection{Definitions}

In order to define the equilibrium concepts formally, we consider a household $h \in P$ and a price system $p \in \mathbb{R}^{\ell}$. For $\mathbf{x}_{\mathbf{h}}=\left(x_{i}\right)_{i \in h} \in \mathcal{X}_{h}$,

$$
p * \mathbf{x}_{\mathbf{h}} \equiv p \cdot\left(\sum_{i \in h} x_{i}\right)
$$

denotes the expenditure of household $h$ on household consumption plan $\mathbf{x}_{\mathbf{h}}$ at the price system $p$. Since as a rule, $p$ and $\mathbf{x}_{\mathbf{h}}$ are of different dimension, we use the $*$-product in lieu of the familiar inner product. Then $h$ 's budget set is defined as

$$
B_{h}(p)=\left\{\mathbf{x}_{\mathbf{h}} \in \mathcal{X}_{h}: p * \mathbf{x}_{\mathbf{h}} \leq p \cdot \omega_{h}\right\}
$$

We next define the efficient budget set $E B_{h}(p)$ as the set of $\mathbf{x}_{\mathbf{h}} \in B_{h}(p)$ with the property that there is no $\mathbf{y}_{\mathbf{h}} \in B_{h}(p)$ such that

$U_{i}\left(\mathbf{y}_{\mathbf{h}} ; h\right) \geq U_{i}\left(\mathbf{x}_{\mathbf{h}} ; h\right)$ for all $i \in h$

$U_{i}\left(\mathbf{y}_{\mathbf{h}} ; h\right)>U_{i}\left(\mathbf{x}_{\mathbf{h}} ; h\right)$ for some $i \in h$. 
Further define a state of the economy as a triple $(p, \mathbf{x} ; P)$ such that $p \in \mathbb{R}^{\ell}$ is a price system and $(\mathbf{x} ; P) \in \mathcal{X} \times P$ is an allocation, i.e. $\mathbf{x}=\left(x_{i}\right)_{i \in I}$ is an allocation of commodities and $P$ is an allocation of consumers (a household structure, a partition of the population into households). A state $(p, \mathbf{x} ; P)$ is a competitive equilibrium with free exit (CEFE) if it satisfies the following conditions:

1. $\mathbf{x}_{\mathbf{h}} \in E B_{h}(p)$ for all $h \in P$.

2. $\sum_{i} x_{i}=\omega_{S}$.

3. There is no $h \in P, i \in h$ and $y_{i} \in B_{\{i\}}(p)$ such that

$$
U_{i}\left(y_{i} ;\{i\}\right)>U_{i}\left(\mathbf{x}_{\mathbf{h}} ; h\right)
$$

Finally a competitive equilibrium with free household formation $(\mathbf{C E F H})$ is a $\mathrm{CEFE}(p, \mathbf{x} ; P)$ that also satisfies:

4. There are no $h$ and $g \in P, i \in h$ and $\mathbf{y}_{\mathbf{g} \cup\{\mathbf{i}\}} \in B_{g \cup\{i\}}(p)$ such that

$$
\begin{aligned}
& U_{j}\left(\mathbf{y}_{\mathbf{g} \cup\{\mathbf{i}\}} ; g \cup\{i\}\right)>U_{j}\left(\mathbf{x}_{\mathbf{g}} ; g\right) \text { for all } j \in g ; \\
& U_{i}\left(\mathbf{y}_{\mathbf{g} \cup\{\mathbf{i}\}} ; g \cup\{i\}\right)>U_{i}\left(\mathbf{x}_{\mathbf{h}} ; h\right) .
\end{aligned}
$$

\subsection{Discussion}

Condition 1 reflects collective rationality in the sense of Chiappori (1988a, 1992), in contrast to the traditional "unitary" model where households are treated like single consumers. Efficient choice by the household refers to the individual consumption and welfare of its members, not merely to the aggregate consumption bundle of the household. Condition 2 requires market clearing. Conditions 1 and 2 alone define a competitive equilibrium $(p, \mathbf{x})$, given household structure $P$, discussed and studied in Haller (2000) and Gersbach and Haller (2001).

In addition, we impose condition 3 that no individual wants to leave a household and participate as a one-member household in the market at the going 
equilibrium prices. Condition 3 constitutes an individual rationality or voluntary participation (membership) constraint. Conditions 1 to 3 together define a competitive equilibrium with free exit.

Conditions 1 to 4 together define a competitive equilibrium with free household formation. Condition 4 requires that no individual can leave a household and can propose a feasible consumption allocation to the members of a new household, created by the individual and another already existing household, which makes everybody in the new household better off at the going equilibrium prices. Condition 4 still presumes that changes of the household structure are the result of individuals leaving a household and proposing a better allocation to an already existing one- or multi-person household. Condition 4 already appears in the earlier literature on coalition formation, beginning with Greenberg (1978) and Drèze and Greenberg (1980) who have introduced the concept of individually stable equilibrium where a coalition partition is individually stable if it is immune to individual movements which benefit the moving player and do not hurt any member of the group she joins. ${ }^{5}$ Finally, our paper is related to the influential work of Hirschman (1970) who has considered the comparative efficiency of the exit and voice options as mechanisms of recuperation. In the absence of externalities, the exit option limits power within households in the sense that a person cannot achieve higher utility as a multi-member household than as an individual market participant. This follows from our first proposition.

One could think of even stronger conditions in the tradition of the matching literature (see Roth and Sotomayor 1990 for surveys) where two persons can break away from two different matches and form a new match. But it has been argued in other contexts, that the divorce threat and thus the exit option alone describes the behavior of individuals in multi-person households; see Bourguignon and Chiappori (1994) for a summary of this debate. Our condition 4 lies between these two perspectives on how individuals decide whether to leave a household. It proves sufficient to put the existence of equilibria with free household formation into question and it is just restrictive enough to make the normative issue how more outside options affect welfare an interesting one.

\footnotetext{
${ }^{5}$ Among recent contributions to that literature using a similar condition are Banerjee, Konishi and Sönmez (2001), Jehiel and Scotchmer (2001), and Bogomolnaia and Jackson (2002). In our work we combine coalition formation, collective decisions and competitive markets.
} 
As it is formulated, condition 4 requires that all members must want the newly formed household $g \cup\{i\}$ with the proposed commodity allocation. Alternatively, one might require that none of the members of the previous household $g$ be opposed to forming the new household, i.e. the inequalities pertaining to $j \in g$ become weak. The two formulations are equivalent under many, but not all circumstances.

\section{Equilibrium Welfare}

\subsection{Inefficacy of Outside Options}

We are interested in the individual's possibilities of achieving higher utility levels by participating in a particular household rather than acting and trading individually or participating in other households. One might conjecture that particular household members with high bargaining power could use the household to obtain more consumption. We commence by examining group formation when there are no externalities (i.e. there is absence of consumption and group externalities). We establish the following neutrality theorem.

\section{Proposition 1 (Neutrality Theorem)}

Suppose absence of externalities and continuity and local non-satiation of consumer preferences. Consider $(p ; \mathbf{x}) \in \mathbb{R}^{\ell} \times \mathcal{X}$ and any household structure $P$. Then the following three assertions are equivalent:

(i) $(p, \mathbf{x} ; P)$ is a competitive equilibrium with free household formation.

(ii) $(p, \mathbf{x} ; P)$ is a competitive equilibrium with free exit.

(iii) $(p, \mathbf{x})$ is a traditional competitive equilibrium where each agent acts and trades individually.

The proof is given in the appendix. Proposition 1 asserts that in the absence of any externalities, free exit implies that a consumer can fare no better and no worse as a member of a multi-member household than as an individual market participant. If, in spite of free exit, some individuals enjoy higher 
utility levels as household members than they would obtain individually, some sort of externality has to be present. Proposition 1 also states that in the absence of any externalities, the set of competitive equilibria with free household formation is essentially equal to the set of (traditional) competitive equilibria when all individuals act and trade individually.

Proposition 1 extends the "Irrelevance Proposition" of Gersbach and Haller (2001). It conforms with intuition, but still requires a proof and has important implications for the role of outside options available to individuals in households operating in competitive commodity markets. If there are no externalities, adding more outside options for agents is irrelevant for consumption and utility allocation and hence for welfare. Suppose e. g. that all multi-person households take their decisions according to a Nash bargaining solution. Then, Proposition 1 says that it is irrelevant whether such bargaining takes place with outside options of the first type (exit) only or with outside options of both types (exit and possibly joining another consenting household). Equally important is the observation that adding more outside options does not impair the stability of households if externalities are absent. The downside is that household formation becomes pointless under these circumstances.

The working of the neutrality theorem is now illustrated by an example. In the example, it is shown that only an equal split of bargaining power between the members of a two-person household is consistent with a CEFE or CEFH. Different distributions of bargaining power are consistent with a market equilibrium where the household structure is fixed and exit is not an option. But those market equilibria violate condition 3 or condition 4 in the above definition of CEFE and CEFH. The example follows.

Example 1. Let $\ell=2, I=\{1,2,3\}$. Preferences are represented by $U_{i}\left(\mathbf{x}_{\mathbf{h}} ; h\right)=u_{i}\left(x_{i}\right)=u_{i}\left(x_{i}^{1}, x_{i}^{2}\right)$ where $x_{i}^{k}$ denotes the quantity of good $k$ $(k=1,2)$ consumed by individual $i$. Specifically, we assume

$$
\begin{aligned}
& U_{1}\left(x_{1}^{1}, x_{1}^{2}\right)=\ln x_{1}^{1}, \\
& U_{2}\left(x_{2}^{1}, x_{2}^{2}\right)=\ln x_{2}^{2}, \\
& U_{3}\left(x_{3}^{1}, x_{3}^{2}\right)=\frac{1}{2} \ln x_{3}^{1}+\frac{1}{2} \ln x_{3}^{2} .
\end{aligned}
$$


We further assume the individual endowments

$$
w_{1}=\left(0, \frac{1}{2}\right), w_{2}=\left(0, \frac{1}{2}\right), w_{3}=(1,0) .
$$

Commodity prices are normalized so that $p_{1}=1$.

Consider first the household structure $P^{0}=\{\{1\},\{2\},\{3\}\}$. It is obvious that there exists a unique market equilibrium $\left(p^{0}, \mathbf{x}^{0} ; P^{0}\right)$, given by:

$$
\begin{aligned}
& p^{0}=(1,1), \\
& x_{1}^{0}=\left(\frac{1}{2}, 0\right), \\
& x_{2}^{0}=\left(0, \frac{1}{2}\right), \\
& x_{3}^{0}=\left(\frac{1}{2}, \frac{1}{2}\right) .
\end{aligned}
$$

Consider next the household structure $P^{*}=\{\{1,2\},\{3\}\}$. Suppose that household $g=\{1,2\}$ maximizes a utilitarian social welfare function

$$
\begin{aligned}
W_{h} & =\alpha U_{1}\left(x_{1}\right)+(1-\alpha) U_{2}\left(x_{2}\right) \\
& =\alpha \ln x_{1}^{1}+(1-\alpha) \ln x_{2}^{2}, \quad 0<\alpha<1,
\end{aligned}
$$

subject to the budget constraint $x_{1}^{1}+p_{2} x_{2}^{2}=p_{2}$. $\alpha$ can be interpreted as the weight of individual 1 in household $g$. Similarly, $1-\alpha$ is the weight of individual 2 in household $g$. The excess demand vectors of the households $g$ and $h=\{3\}$, denoted by $z_{g}$ and $z_{h}$, are given by

$$
\begin{aligned}
& z_{g}=\left(\alpha p_{2},-\alpha\right), \\
& z_{h}=\left(-\frac{1}{2}, \frac{1}{2 p_{2}}\right) .
\end{aligned}
$$

A market equilibrium without exit $\left(p^{*}, \mathbf{x}^{*} ; P^{*}\right)$ would require

$$
\begin{aligned}
p^{*} & =\left(1, \frac{1}{2 \alpha}\right), \\
x_{1}^{*} & =\left(\frac{1}{2}, 0\right), \\
x_{2}^{*} & =(0,1-\alpha), \\
x_{3}^{*} & =\left(\frac{1}{2}, \alpha\right) .
\end{aligned}
$$


At prices $p^{*}$, individuals $i=1,2$ could obtain the following consumption vectors $x_{1}^{s}$ and $x_{2}^{s}$ by leaving household $g$ :

$$
\begin{aligned}
& x_{1}^{s}=\left(\frac{1}{4 \alpha}, 0\right), \\
& x_{2}^{s}=\left(0, \frac{1}{2}\right) .
\end{aligned}
$$

Except for $\alpha=\frac{1}{2}$, either $U_{1}\left(x_{1}^{s}\right)>U_{1}\left(x_{1}^{*}\right)$ or $U_{2}\left(x_{2}^{s}\right)>U_{2}\left(x_{2}^{*}\right)$ and, hence, $\left(p^{*}, \mathbf{x}^{*} ; P^{*}\right)$ is a competitive equilibrium with exit only for $\alpha=\frac{1}{2}$. In this case, $x_{1}^{*}=x_{1}^{0}$ and $x_{2}^{*}=x_{2}^{0}$. Similarly $\left(p^{*}, \mathbf{x}^{*} ; P^{*}\right)$ is a competitive equilibrium with free household formation if and only if $\alpha=\frac{1}{2}$.

\subsection{Optimality of CEFE}

The present paper focuses on the interaction of three allocation mechanisms: group formation, collective decisions within groups and competitive market exchange between groups. Which allocations qualify as optimal or efficient depends on how much freedom a social planner is granted in allocating resources and people. If a social planner can allocate both commodities and consumers, we obtain unconstrained or full Pareto optimality. Accordingly, an allocation $(\mathbf{x} ; P)$ is called fully Pareto-optimal or an optimum optimorum, if "there is no better one", i.e. if

(i) $(\mathbf{x} ; P)$ is feasible and

(ii) there is no feasible allocation $\left(\mathbf{x}^{\prime} ; P^{\prime}\right)$ satisfying $\left(U_{i}\left(\mathbf{x}^{\prime} ; P^{\prime}\right)\right)_{i \in I}>\left(U_{i}(\mathbf{x} ; P)\right)_{i \in I}$.

Denote by $\mathcal{M}^{*}$ the set of fully Pareto-optimal allocations. If all utility functions are continuous in consumption, $\mathcal{M}^{*}$ is not empty [Gersbach and Haller (2001)].

It is obvious that competitive equilibrium allocations with free exit need not be fully Pareto-optimal. Suppose e.g. that there are large gains from forming a two-person household because two individuals, say agent 1 and 2 , have positive pure group externalities. No further externalities are present in the economy. Moreover, suppose that both agents have the same endowments and the same consumption preferences. A competitive equilibrium with free 
exit can have every person live in a single-person household. This equilibrium is, however, Pareto inefficient. Agent 1 and 2 could form a two-person household with a household excess demand function equal to the sum of individual excess demand functions. Hence, equilibrium prices and consumption allocation would remain as if all persons lived in single-person households. Hence, agent 1 and 2 would be better off while all other individuals receive the same utility. The example suggests that the lack of appropriate outside options causes inefficiency of CEFE. It also suggests that a pair of CEFE can be Pareto-rankable. ${ }^{6}$ In the next section we discuss CEFH.

\subsection{Welfare Implications of Adding JO}

We have seen that adding outside options is irrelevant if there are no externalities. Now we are going to examine the consequences of adding more outside options in the presence of externalities. Clearly the additional requirement can eliminate some of the competitive equilibria with free exit. But which ones? The good ones, the bad ones, all or none? We shall demonstrate by means of examples that each of the four conceivable alternatives is indeed possible.

We have already seen that under the hypothesis of Proposition 1, none of the equilibria is eliminated. In section 5 , we consider examples where all equilibria are eliminated. It remains to demonstrate the other two possibilities. Let us first examine an example that exhibits a pair of weakly Pareto-rankable competitive equilibria with free exit where the inferior one is also a competitive equilibrium with free household formation whereas the superior one is not. Subsequently, we modify the example so that the superior competitive equilibrium with free exit turns out to be a competitive equilibrium with free household formation while the inferior equilibrium is eliminated by the additional requirement.

In both examples, the prospect of a tiny surplus share induces a currently single person to form a two-person household, leaving most of the surplus to the new partner. With a population of three people, this leads to the break-up of any existing two-person household and formation of a new one if the opportunity arises, that is if the joining option becomes available. In contrast,

\footnotetext{
${ }^{6}$ It is an open question under which circumstances at least one fully Pareto-optimal equilibrium allocation exists.
} 
the members of a three-person household have no other household to join in a population of three people; thus the three-person household remains unaffected by the introduction of the joining option. One can fix the household structure associated with a Pareto-superior competitive equilibrium with free exit by varying (primarily) the per capita surplus in three-person households.

Example 2. Let $I=\{1,2,3\}$ and $\ell=1$. For a household $h$, let the endowment be $\omega_{h}=|h|$. Let preferences have utility representations of the form

$$
U_{i}\left(\mathbf{x}_{\mathbf{h}} ; h\right)=a(|h|) \cdot x_{i}
$$

for consumer $i$ in household $h$ where $a(1)=2, a(2)=8, a(3)=5$. Since there is only one good and preferences are strictly monotone, we can set $p=1$. First consider the competitive equilibrium with free exit $E^{1}=$ $(p ;(1,1,1) ;\{\{1\},\{2,3\}\})$ with utility allocation $(2,8,8)$. Next consider the CEFE $E^{2}=(p ;(0.4,1.3,1.3) ;\{I\})$ with utility allocation $(2,6.5,6.5)$. Then $E^{1}$ weakly Pareto-dominates $E^{2}$. The inferior equilibrium is also a CEFH, since there is no other household to join. However, the superior equilibrium is not a CEFH. Namely individual 2 can propose to consumer 1 to form household $\{1,2\}$ with consumption $y_{1}=1 / 2, y_{2}=3 / 2$ which makes both better off.

Example 3. Let again $I=\{1,2,3\}$ and $\ell=1$. Modify the previous example by setting $a(1)=1, a(2)=8, a(3)=6$. Take $E^{1}$ as before, now with utility allocation $(1,8,8)$. Set $E^{2}=(p ;(1 / 5,7 / 5,7 / 5) ;\{I\})$ which is an efficient CEFH, with utility allocation $(1.2,8.4,8.4)$. Here $E^{1}$ is strictly dominated by $E^{2}$ and is not a CEFH.

The preceding examples highlight the ambivalent implications of adding more outside options for everybody in a society. There exist constellations where everybody is worse off. Nevertheless, there are clear circumstances where adding more outside options is not detrimental to welfare, where in fact some equilibria with free household formation are fully Pareto-optimal. For the purpose of describing such a situation, let us call $P \in \mathcal{P}$ an optimal household structure, if there exists a feasible $\mathbf{x}$ such that $(\mathbf{x} ; P)$ is a fully Pareto-optimal allocation, i.e. $(\mathbf{x} ; P) \in \mathcal{M}^{*}$. Then we obtain: 
Proposition 2 Suppose pure group externalities, that is $U_{i}\left(\mathbf{x}_{\mathbf{h}} ; h\right)=U_{i}^{c}\left(x_{i}\right)+U_{i}^{g}(h)$ for $\mathbf{x}_{\mathbf{h}} \in \mathcal{X}_{h}, h \in \mathcal{H}_{i}$. If

(i) $(p, \mathbf{x})$ is a competitive equilibrium of the pure exchange economy represented by $\left(U_{i}^{c}, \omega_{\{i\}}\right)_{i \in I}$, all $U_{i}^{c}, i \in I$, satisfy local non-satiation, and

(ii) $P$ is the unique optimal household structure based solely on group preferences represented by $U_{i}^{g}, i \in I$,

then the allocation $(\mathbf{x} ; P)$ is fully Pareto-optimal and the state $(p, \mathbf{x} ; P)$ is a CEFH.

The proof is given in the appendix. Proposition 2 means that free household formation will never destroy all Pareto-optimal allocations if there is a single optimal household structure based on group preferences alone. In that case, the equilibrium condition 4 tends to eliminate some inefficient equilibria associated with inefficient household structures. The latter occurs in the following example: Adding the second type of outside options leads to the reshuffling of an inefficient household structure that can prevail as long as only the first type of outside options is available to individuals. Once the joining option becomes available as well, one individual joins another household which leads to the establishment of the optimal household structure.

Example 4. Let $I=\{1,2,3\}$ and $\ell=1$. For a household $h$, the endowment is $w_{h}=|h|$. Preferences are represented by utility functions $U_{i}, i \in I$, and given as follows:

$$
\begin{aligned}
& U_{i}\left(\mathbf{x}_{\mathbf{h}} ; h\right)=x_{i}+k \quad \text { if } h=\{1,2\} \\
& U_{i}\left(\mathbf{x}_{\mathbf{h}} ; h\right)=x_{i}-k \quad \text { if }|h|=3 \\
& U_{i}\left(\mathbf{x}_{\mathbf{h}} ; h\right)=x_{i} \quad \text { otherwise }
\end{aligned}
$$

The group externalities satisfy $1>k>0$. Since there is only one commodity, we can set $p=1$. Note that there exists a uniquely determined optimal household structure $P^{*}=\{\{1,2\},\{3\}\}$, based on pure group preferences alone. However, there also exists the CEFE

$$
E^{1}=(p,(1,1,1) ;\{\{1,3\}, 2\})
$$


with a different household structure and utility allocation $(1,1,1)$. The respective equilibrium allocation is, for instance, dominated by the fully Paretooptimal allocation

$$
((1-k / 2,1-k / 2,1+k) ;\{\{1,2\},\{3\}\})
$$

with utility allocation $(1+k / 2,1+1 / 2,1+k)$. Moreover, $E^{1}$ is not a $\mathrm{CEFH}$ since the first and second individual could form a new household providing higher utility for both. Indeed, it is obvious that any allocation $(\mathbf{x} ; P)$ with $P \neq P^{*}$ cannot be a competitive equilibrium allocation with free household formation.

\section{Existence with EO}

In this section we establish the existence of competitive equilibria with free exit. For that purpose, we denote by $P^{0}=\{\{1\}, \ldots,\{n\}\}$ the household structure where all households are singletons and formulate a first equilibrium existence theorem.

Proposition 3 (Trivial Equilibria) Suppose for all $i \in I$ :

(i) $\omega_{i} \gg 0$.

(ii) $U_{i}\left(x_{i} ;\{i\}\right)$ is continuous, strictly monotone and concave in $x_{i}$.

Then there exists a competitive equilibrium with free exit of the form $\left(p ; \mathbf{x} ; P^{0}\right)$.

PROOF. As an immediate consequence of Proposition 1 in Gersbach and Haller (1999) or as a corollary of the proof of Proposition 4 given in the appendix, we obtain existence of a price system $p$ and an allocation $\mathbf{x}$ so that conditions 1 and 2 for a competitive equilibrium with free exit are satisfied. We need not check condition 3, since all individuals are already in one-person households which renders the exit option irrelevant. Q.E.D.

The proposition asserts the existence of trivial competitive equilibria with exit where everybody is single and is not exposed to externalities. We also 
know that under the provisions of the neutrality theorem, any household structure qualifies as equilibrium household structure, provided there is an equilibrium. Otherwise, for multi-member households to exist in equilibrium, there ought to be some incentive for multi-member household formation, some advantage from living in a larger household that prevents its members from leaving.

A priori, a large group or, to be precise, a non-single household $h$ offers an advantage to its members if at any given price system, the group can afford consumption plans for its members that make each member better off than the member's optimal choice as a single consumer - which is captured by inequalities of the form (3) below. If preferences are assumed convex and continuous in household consumption, then under certain additional assumptions, Debreu's (1952) social equilibrium approach to the equilibrium existence problem proves most suitable. ${ }^{7}$ Essentially it suffices to assume that every member $i$ of multi-member household $h$ prefers the consumption plan $\mathbf{x}_{\mathbf{h}}=\left(x_{j}\right)_{j \in h}$ for the household to consuming the individual component $x_{i}$ of $\mathbf{x}_{\mathrm{h}}$ as a single person. But one crucial step in the social equilibrium approach is the restriction to truncated budget sets. This technicality makes the formal definition of the Large Group Advantage (LGA) condition below more complicated and elaborate, since one has to make sure that the inequalities (3) can be met even if household $h$ is restricted to a truncated budget set. Formally, this requirement is captured by the following conditions 1-3. To this end, we restrict prices to the price simplex

$$
\Delta=\left\{p \in \mathbb{R}_{+}^{\ell}: \sum_{k=1}^{\ell} p^{k}=1\right\} .
$$

We denote the relative interior of $\Delta$ by $\Delta^{o}$. Further let us choose $k>0$ so that the social endowment $\omega_{S}$ belongs to the cube $Q=[0, k]^{\ell}$. Set $K=[0,2 k]^{\ell}$.

\footnotetext{
${ }^{7}$ We shall elaborate later on an alternative approach relying on the "excess demand lemma" which proves successful under different assumptions, including specific positive externalities of the separable type within household $h$. Without separability and purely positive externalities, the social equilibrium approach of Debreu is more promising.
} 
(LGA) Large Group Advantage: We say that a multi-member household $h$ has large group advantage, if:

1. Every member $i \in h$ has a demand function $x_{i}^{0}(\cdot)$, where $x_{i}^{0}(p)$ denotes the demand of consumer $i$ when trading individually from the endowment $\omega_{\{i\}}$ at prices $p \in \Delta^{o}$.

2. For every price system $p \in \Delta$, there exists a non-empty, compact and convex set $X_{h}(p) \subseteq B_{h}(p) \cap K^{h}$ which depends continuously on $p$.

3. For all $p \in \Delta^{o}$ and $\mathbf{x}_{\mathbf{h}} \in B_{h}(p) \cap K^{h}: \mathbf{x}_{\mathbf{h}} \in X_{h}(p)$ iff

$$
U_{i}\left(\mathbf{x}_{\mathbf{h}} ; h\right)-U_{i}\left(x_{i}^{0}(p) ;\{i\}\right) \geq \delta_{i}(p)
$$

with some threshold $\delta_{i}(p) \geq 0$ holds for all $i \in h$.

To illustrate that the key condition 3 of LGA is non-vacuous, let us present two alternative assumptions on a multi-member household $h$ that will yield condition 3 when supplemented with suitable further assumptions: (i) Sufficiently bounded individual demands so that $\left(x_{i}^{0}(p)\right)_{i \in h} \in B_{h}(p) \cap K^{h}$. An example is given by the utility representation $U_{i}\left(x_{i} ;\{i\}\right)=\min \left\{x_{i}^{k} \mid k=1, \ldots, \ell\right\}$. (ii) Group preferences which strictly dominate consumption preferences, e.g. $U_{i}(\cdot ; h) \geq 0$ and $U_{i}(\cdot ;\{i\})<0$ for $i \in h$. In this case, (3) becomes trivial. An example with $U_{i}(\cdot ;\{i\})<0$ is given by $U_{i}\left(x_{i} ;\{i\}\right)=-\sum_{k} \exp \left(-x_{i}^{k}\right)$. The somewhat extreme cases (i) and (ii) have the virtue of being simple and transparent. In the appendix we show:

Proposition 4 (Non-Trivial Equilibria) Suppose:

(i) $\omega_{h} \gg 0$ for all $h \in \mathcal{H}$.

(ii) $U_{i}\left(\mathbf{x}_{\mathbf{h}} ; h\right)$ is continuous and concave for all $i \in h, h \in \mathcal{H}$.

(iii) $U_{i}\left(x_{i} ;\{i\}\right)$ is strictly monotone for all $i \in I$.

(iv) There exist a household $h \in \mathcal{H}$ with $1<|h|<n$, which has large group advantage (LGA), and a member $j \in h$ whose preferences are strictly monotonic in own consumption and who is not imposing any negative consumption externalities on other household members. 
Then there exists a competitive equilibrium with free exit of the form $(p, \mathbf{x} ; P)$ with $P \neq P^{0}$. More specifically, $h \in P$ for some $h$ satisfying (iv).

The proposition basically states that as soon as two or more agents can gain from living together in a household, non-trivial equilibria with free exit and a multi-member household exist. Needless to say that one can also impose conditions so that only small groups are viable in an equilibrium with free exit.

As mentioned in footnote 7 , with different assumptions an approach relying on the "excess demand lemma" proves successful. Specifically, one makes certain standard assumptions (including strict concavity of the functions $\left.U_{i}(\cdot ;\{i\})\right)$ in combination with particular positive externalities of the separable type within household $h$. Two special cases of the latter are positive pure group externalities [PGE restricted to household $h$ ] on the one hand and positive separable pure consumption externalites [SEP of Haller (2000) restricted to household $h$ ] on the other hand. The proof is similar to that of Proposition 3 in Gersbach and Haller (1999).

\section{Existence with EO and JO}

In this section we take up the challenging question whether and under which circumstances competitive equilibria with free household formation exist. We start with the observation that Proposition 2 lends itself to an existence result.

Proposition 5 Suppose pure group externalities, that is $U_{i}\left(\mathbf{x}_{\mathbf{h}} ; h\right)=U_{i}^{c}\left(x_{i}\right)+U_{i}^{g}(h)$ for $\mathbf{x}_{\mathbf{h}} \in \mathcal{X}_{h}, h \in \mathcal{H}_{i}$. If

(i) $\omega_{S} \gg 0$, each of the functions $U_{i}^{c}, i \in I$, is continuous, strictly increasing and strictly quasi-concave, and

(ii) $P$ is the unique optimal household structure based solely on group preferences represented by $U_{i}^{g}, i \in I$,

then a fully Pareto-optimal CEFH exists. 
PROOF. By Proposition 17.C.1 of Mas-Colell et al. (1995), there exists a competitive equilibrium $(p, \mathbf{x})$ of the pure exchange economy represented by $\left(U_{i}^{c}, \omega_{\{i\}}\right)_{i \in I}$ if (i) holds. By Proposition 2 above, the allocation $(\mathbf{x} ; P)$ is fully Pareto-optimal and the state $(p, \mathbf{x} ; P)$ is a CEFH if (i) and (ii) hold. Q.E.D.

Next we make the important observation that there are constellations where competitive equilibria with free household formation need not exist, where all conceivable household structures are destabilized by outside options of the second type (JO). Therein lies the challenge.

\subsection{Non-Existence of Equilibria with Free Household Formation: An Example}

We are going to present an example that exhibits pure group externalities. There is also a single consumption good. Consequently, in equilibrium no trade occurs across households, but utility can be (imperfectly) transferred between members of the same household. For each household, one can determine the feasible utility allocations for its members. Hence by varying the consumptive utility function $u$ and the group externality parameters $k$ and $\epsilon$ of the example, one can generate an entire family of hedonic coalition games in the sense of Drèze and Greenberg (1980). A transferable utility game results if (and only if) $u$ is affine linear.

In the specific four-person example, surplus comparisons suggest that households of any size are unstable and, therefore, disqualify as equilibrium outcomes. A four-person household is unstable because it generates negative surplus and at least one of its members can fare better going single. A three-person household is unstable, since at least one member can benefit from forming a two-person household with the currently single individual and appropriate most of the surplus. This is possible because in a twoperson household, the maximum per capita surplus is not much less than in a three-person household. But two coexisting two-person households do not constitute a stable configuration either, since at least one person will have an incentive to switch households. This is the case because every three-person household includes at least one person with a preference for three-person households so that the maximum per capita surplus in such a household exceeds the maximum per capita surplus in a two-person household. Finally, 
two singles can always benefit from forming a two-person household. Thus a household proves unstable regardless of size.

Example 5. Let $I=\{1,2,3,4\}$ and $\ell=1$. For a household $h$, the endowment is $w_{h}=|h|$. Preferences are represented by utility functions $U_{i}, i \in I$, and given as follows:

$$
\begin{aligned}
& U_{i}\left(\mathbf{x}_{\mathbf{h}} ; h\right)=u\left(x_{i}\right) \quad \text { if } h=\{i\} \\
& U_{i}\left(\mathbf{x}_{\mathbf{h}} ; h\right)=u\left(x_{i}\right)+k \quad \text { if }|h|=2 \\
& U_{i}\left(\mathbf{x}_{\mathbf{h}} ; h\right)=u\left(x_{i}\right)+k \quad \text { if }|h|=3, i=1,2 \\
& U_{i}\left(\mathbf{x}_{\mathbf{h}} ; h\right)=u\left(x_{i}\right)+k+\varepsilon \text { if }|h|=3, i=3,4 \\
& U_{i}\left(\mathbf{x}_{\mathbf{h}} ; h\right)=u\left(x_{i}\right)-k \quad \text { if }|h|=4
\end{aligned}
$$

The group externalities satisfy $k>0$ and $k \geq \varepsilon \geq 0$. The function $u$ is continuous and strictly increasing. It satisfies $u(1) \geq u(0)+k$. Since there is only one good, we can set $p=1$.

We first consider the case $\varepsilon=0$. Then, there exists a CEFH, namely

$$
E^{1}=(p ;(1,1,1,1) ;\{\{1,2\},\{3,4\}\})
$$

with utility allocation $(u(1)+k, u(1)+k, u(1)+k, u(1)+k)$. Since the population is homogeneous, there exist two other equilibria with the same utility allocation and household structures $\{\{1,3\},\{2,4\}\}$ and $\{\{1,4\},\{2,3\}\}$, respectively. No other equilibria with free household formation exist. For instance, the household structure $\{\{1,2,3\}, 4\}$ cannot be part of an equilibrium, since at least one individual in the household $\{1,2,3\}$ can propose to agent $i=4$ to form a two-person household which makes both individuals better off. Specifically, the individual leaving $\{1,2,3\}$ can offer $i=4$ a consumption level $u^{-1}(u(1)-k+\delta)$ for some small $\delta, k>\delta>0$. Agent 4's utility will be $u(1)+\delta$ and therefore larger than in the candidate equilibrium. The deviating agent obtains a utility

$$
u\left(2-u^{-1}(u(1)-k+\delta)\right)+k
$$

which exceeds the utility of at least one member in the household $\{1,2,3\}$ since $\delta<k$. 
Next let us consider the case $\varepsilon>0$ where $\varepsilon$ is sufficiently small. We claim that no $\mathrm{CEFH}$ exists. Consider first the candidate equilibrium $E^{1}$. Individual 2 could join $\{3,4\}$ by proposing the household allocation:

$$
x_{g}=\left(x_{2}, x_{3}, x_{4}\right)=\left(3-2 u^{-1}(u(1)-\varepsilon), u^{-1}(u(1)-\varepsilon), u^{-1}(u(1)-\varepsilon)\right)
$$

which yields the utility allocation

$$
\left(u\left(3-2 u^{-1}(u(1)-\varepsilon)\right)+k, u(1)+k, u(1)+k\right)
$$

and makes agent 2 better off while the utility of individuals 3 and 4 remains constant. Hence, $E^{1}$ cannot be a CEFH. A similar argument applies mutatis mutandis for any other household structure with two two-person households. Furthermore, by essentially the same agument as before, no CEFH can exist with a three-person or four-person household. Finally, if everybody were alone, two persons could form a household and both be better off. Therefore, no CEFH exists.

The interesting feature of the example is that a small change of the externalities destroys the existence of a competitive equilibrium with free household formation. It is obvious that the existence problem in the example can be overcome by taking a specific number of replica of the original economy. In the example three replica would allow all individuals preferring a three-person household over a two-person household to be member of a threeperson household while other individuals could live in two-person households. Later, however, we will see that enlarging the economy through replication cannot restore existence under all circumstances.

\subsection{Existence with One Commodity}

Having established the possibility of non-existence, we next identify circumstances in which a competitive equilibrium with free household formation exists. We first provide several simple existence results when trade of consumption goods does not matter, because there is only one commodity. Subsequently, the more challenging case of more than one commodity is considered. 


\subsubsection{Hedonic Coalitions}

If there is only one commodity, the model is equivalent to a game with "hedonic coalitions" à la Drèze and Greenberg (1980) where trade and transfers among coalitions are prohibited. Their concept of individually stable equilibrium (i.s.e.) is slighty stronger than our notion of competitive equilibrium with free household formation (CEFH). Their Example 3.1 and our Examples 5 and 6 are all instances of non-existence of a CEFH. (and by implication, an i.s.e.).

The construction of Examples 1 and 2 generalizes and yields a first immediate existence result. Let $I=\{1, \ldots, n\}$ and $\ell=1$. Further, let preferences have utility representations of the form

$$
U_{i}\left(\mathbf{x}_{\mathbf{h}} ; h\right)=A(h) \cdot x_{i}
$$

for consumer $i$ in household $h$ where the externality coefficient $A(h)>0$ represents a multiplicatively separable group externality within household $h$ - which is ordinally equivalent to a pure group externality. One obtains as an immediate result:

Proposition 6 If $P$ is a household structure such that

$$
A(h) \cdot \omega_{h} \geq \sum_{i \in h} A(\{i\}) \cdot \omega_{\{i\}}
$$

for all $h \in P$, then there exists a competitive equilibrium with free exit with household structure $P$. If in particular, the inequality holds for $h=I$, then there exists a competitive equilibrium with free household formation where the household I is formed.

\subsubsection{Two-sided Matching}

Next we deal with the existence of competitive equilibria with free household formation in the marriage market. The marriage market has been a prominent application of the two-sided matching approach [see Roth and Sotomayor (1990)]. Gale and Shapley (1962) have shown in their seminal paper that there always exists a stable matching for any marriage market. Many subsequent contributions have demonstrated the robustness of this 
classic result. We have already pointed out that condition 4 in our definition of a competitive equilibrium with free household formation (CEFE) is weaker than the stability condition in the matching literature [see Roth and Sotomayor (1990)] which requires that a matching be not blocked by any individual or pair of agents forming a new match. Therefore, this literature promises to provide further existence results in our context. Indeed, the existence results carry over from the matching literature to our framework when there is only one commodity.

To state such a result in our context we consider a simple marriage market as follows. We suppose $\ell=1$ and that the population is divided into two non-empty, finite and disjoint sets, $M$ and $F: M=\left\{m_{1}, \ldots, m_{m}\right\}$ is the set of men, and $F=\left\{f_{1}, \ldots, f_{n}\right\}$ is the set of women. We assume that each individual has some endowments, $\omega_{i}>0$ and $\omega_{j}>0$, respectively. The preferences of men are given by

$$
\begin{aligned}
& U_{i}\left(\mathbf{x}_{\mathbf{h}} ; h\right)=x_{i} \quad \text { if } h=\left\{m_{i}\right\} \\
& U_{i}\left(\mathbf{x}_{\mathbf{h}} ; h\right)=x_{i}+g_{i j} \quad \text { if } h=\left\{m_{i}, f_{j}\right\} \\
& U_{i}\left(\mathbf{x}_{\mathbf{h}} ; h\right)=x_{i}-\bar{g} \quad \text { in all other cases }
\end{aligned}
$$

We assume $\bar{g}>0$ and $0 \leq g_{i j} \leq \omega_{i}$ for any potential couple $\left\{m_{i}, f_{j}\right\}$. The preferences of women are defined accordingly. We call such preferences pure group externalities of the matching type.

Such a marriage market where utility can be freely transferred within a household by an appropriate allocation of commodities and no trade through markets occurs, can be viewed as a generalized assignment game. We obtain:

Proposition 7 Suppose $\ell=1$ and pure group externalities of the matching type. Then a competitive equilibrium with free household formation exists.

PROOF. Because of the exit condition 3 and $\bar{g}>0$, we only have to consider single person households or matches between a man and a woman as potential households in a CEFH. Since our free household formation condition 4 is weaker than the stability condition in the matching literature we can rely on the existence proofs for the generalizations and variations of the assignment model provided by Shapley and Shubik (1972), Quinzii (1984), Gale (1984) and Alkan and Gale (1990); see also Roth and Sotomayor (1990). 
Let us check the essential assumptions as they are formulated in Alkan and Gale (1990), for example. Let us hypothetically extend the domain of $U_{i}$ to negative consumption - which will not occur in equilibrium. Then the range of the utility function is all of $\mathbb{R}$, since $U_{i}\left(x_{i}\right)$ is unbounded above and below. Moreover, for any couple, the corresponding Pareto-frontier in utility space is linear. Hence, we can apply Theorem 1 of Alkan and Gale (1990) which establishes existence of a core payoff and, consequently, of a CEFH. Q.E.D.

\subsection{Non-Existence in the Marriage Market}

When investigating the stable matching problem in our framework, where not only individuals are matched through the market but also commodities are traded and collective household decisions are taken, one encounters a number of new problems.

We have seen that the existence results of the matching literature are applicable in our framework provided that there is only one commodity. With several commodities, however, households may actively trade in the market. Consequently, what is feasible for a household depends on market prices. This price-dependence tends to undermine existence, even if households are restricted to singles and heterosexual marriages. Although our equilibrium conditions 3 and 4 are weaker than the standard stability condition for the marriage market, the existence result for the special case $\ell=1$ does not carry over to the multiple goods case as the following example demonstrates. In the three-person example, externalities are confined to the one female individual whom we shall call Anita. She experiences a positive group externality and a negative consumption externality (with respect to the second good) when living with a partner. For any constant consumption of the partner, the consumption externality becomes less severe as Anita's consumption of the second good increases.

If everyone is single, the market clearing price of the second good happens to be low. Then at the going prices, Anita can afford enough own consumption of the second good so that the positive group externality dominates and she and another individual can both benefit from forming a two-person household. Now suppose Anita belongs to a two-person household with one single person remaining. Then the market is cleared at a high relative price of the second good, Anita can afford too little consumption of the second good, 
the negative consumption externality dominates, and she is better off alone. Hence for any given household structure, the market clearing prices are such that Anita can benefit from a change of household.

Example 6. Let $\ell=2$ and $I=\{1,2,3\}$ where the first two individuals are male and $i=3$ is Anita, the only female. The individual endowments are given by:

$$
w_{1}=(0,1), w_{2}=(0,1), w_{3}=(1,1) .
$$

Preferences are represented by utility functions of the form $U_{i}\left(\mathbf{x}_{\mathbf{h}} ; h\right)$. Specifically,

$$
\begin{array}{ll}
U_{1}\left(\mathbf{x}_{\mathbf{h}} ; h\right)=\ln x_{1}^{2}, & \text { if } h=\{1\},\{1,3\} ; \\
U_{2}\left(\mathbf{x}_{\mathbf{h}} ; h\right)=\ln x_{2}^{2}, & \text { if } h=\{2\},\{2,3\} ; \\
U_{3}\left(\mathbf{x}_{\mathbf{h}} ; h\right)=\alpha \ln x_{3}^{1}+(1-\alpha) \ln x_{3}^{2}, & \text { if } h=\{3\} ; \\
U_{3}\left(\mathbf{x}_{\mathbf{h}} ; h\right)=\alpha \ln x_{3}^{1}+(1-\alpha) \ln \left(\max \left\{0, x_{3}^{2}-k x_{i}^{2}\right\}\right)+g, & \text { if } h=\{3, i\}, i=1,2 .
\end{array}
$$

where $0<\alpha<1, x_{i}^{j}$ denotes the quantity of $\operatorname{good} j(j=1,2)$ consumed by individual $i$, and we adhere to the convention $\ln 0=-\infty$.

Living in a two-person household with partner $i=1$ or partner $i=2$ provides the third individual with a positive group externality $(g>0)$. She suffers, however, from a negative consumption externality $(1>k>0)$. We further assume that living in a three-person household or in $h=\{1,2\}$ creates enormous negative group externalities and will never be chosen. Hence our model is of the matching type where the only conceivable household structures consist of single-person and two-person households.

Commodity prices are normalized so that $p_{1}=1$. Consider first the household structure $P^{\circ}=\{\{1\},\{2\},\{3\}\}$. It is obvious that there exists a unique competitive equilibrium $\left(p^{0}, \mathbf{x}^{\mathbf{0}}\right)$ relative to $P^{\circ}$ given by:

$$
\begin{aligned}
& p^{0}=\left(1, p_{2}^{0}\right) \\
& x_{1}^{0}=(0,1) \\
& x_{2}^{0}=(0,1) \\
& x_{3}^{0}=(1,1)
\end{aligned}
$$

To determine the market clearing price, we observe that the demand $x_{3}^{2}$ is given by

$$
x_{3}^{2}=(1-\alpha)\left(1+p_{2}\right) / p_{2} .
$$


Therefore market clearing, $x_{3}^{2}=1$, yields $p_{2}^{0}=\frac{1-\alpha}{\alpha}$. At the going equilibrium prices $i=3$ could propose to $i=1$ to form the household $h=\{1,3\}$ by offering $i=3$ one unit of commodity 2 . The remaining problem of individual 3 is

$$
\begin{aligned}
& \max \left\{\alpha \ln x_{3}^{1}+(1-\alpha) \ln \left(\max \left\{0, x_{3}^{2}-k\right\}\right)+g\right\} \\
& \text { s.t. } x_{3}^{1}+p_{2}^{0} x_{3}^{2}=1+p_{2}^{0} .
\end{aligned}
$$

The solution is

$$
\begin{array}{lcl}
\hat{x}_{3}^{2}=(1-\alpha)\left(1+p_{2}^{0}\right) / p_{2}^{0}+\alpha k & =1+\alpha k, \\
\hat{x}_{3}^{1} & =1+p_{2}^{0}-p_{2}^{0} x_{3}^{2} & =1-(1-\alpha) k
\end{array}
$$

which yields utility

$U_{3}\left(\hat{\mathbf{x}}_{\mathbf{h}} ; h\right)=\alpha \ln (1-(1-\alpha) k)+(1-\alpha) \ln (1-(1-\alpha) k)+g=\ln (1-(1-\alpha) k)+g$.

Suppose that we choose parameters $(k, g)$ such that

$$
\ln (1-(1-\alpha) k)+g>0
$$

Then $\left(p^{0}, \mathbf{x}^{\mathbf{0}} ; \mathrm{P}^{\circ}\right)$ is not a competitive equilibrium with free household formation because $h=\{1,3\}$ will be formed at equilibrium prices.

Consider next the household structure $P^{*}=\{\{1,3\},\{2\}\}$. Consider household $h=\{1,3\}$. The maximal utility the third individual can achieve, subject to 1 's outside options, is attained when individual $i=1$ consumes one unit of the second commodity. The remaining problem of individual 3 is as in the case before. Therefore we obtain the demand for the second commodity as

$$
x_{3}^{2}=(1-\alpha)\left(1+p_{2}\right) / p_{2}+\alpha k .
$$

But to be in equilibrium now, markets must clear again. Hence $x_{3}^{1}=1, x_{3}^{2}=1$ which requires equilibrium prices $p_{2}^{*}=\frac{1-\alpha}{\alpha(1-k)}$. The utility of individual 3 is

$$
U_{3}\left(\mathbf{x}_{\mathbf{h}}^{*} ; h\right)=(1-\alpha) \ln (1-k)+g .
$$

Since there exist values of $\alpha$ such that

$$
\ln (1-(1-\alpha) k)>(1-\alpha) \ln (1-k)
$$


e.g. $\alpha=\frac{1}{2}$, we can fix such an $\alpha$ and choose parameter constellations $(k, g)$ such that

$$
U_{3}\left(\hat{\mathbf{x}}_{\mathbf{h}} ; h\right)>0>U_{3}\left(\mathbf{x}_{\mathbf{h}}^{*} ; h\right) .
$$

Since individual 3 can always achieve utility $U_{3}=0$ by living as a oneperson household and consuming her endowments, we conclude that under the suitably chosen parameter constellation $\left(p^{*}, \mathbf{x}^{*} ; P^{*}\right)$ is not a competitive equilibrium with free household formation: agent 3 prefers to be single at the going market prices. However, we have established before that agent 3 prefers to form a two-person household at the market prices which would obtain if everybody were single. Since individuals 1 and 2 are completely interchangeable, we conclude that no $\mathrm{CEFH}$ exists.

This example shows that active trade across household poses a challenge with regard to existence of stable outcomes not only for us, but also for the traditional matching literature. The hypotheses of the example and of Proposition 7 differ in two respects. First, there are several commodities. Second, there are no longer pure group externalities of the matching type. This begs the question whether existence of a CEFH can be obtained, if there are several commodities, but pure group externalities of the matching type prevail. In the most general form of the latter case, the population is partitioned into men and women; preferences are represented by $U_{i}\left(\mathbf{x}_{\mathbf{h}} ; h\right)=$ $U_{i}^{c}\left(x_{i}\right)+U_{i}^{g}(h)$ such that based on the group preferences given by $U_{i}^{g}$ alone, individual $i$ strictly prefers staying single or forming a two-person household with a member of the opposite sex ("marriage") to any other household. Under these circumstances, the following proposition holds whose proof is straightforward.

Proposition 8 Suppose the general case of pure group externalities of the matching type. If

(i) $(p, \mathbf{x})$ is a competitive equilibrium of the pure exchange economy represented by $\left(U_{i}^{c}, w_{\{i\}}\right)_{i \in I}$ and

(ii) $P$ is a stable matching with respect to pure group preferences,

then the state $(p, \mathbf{x} ; P)$ is a CEFE. 
According to the classical result of Gale and Shapley (1962), condition (ii) can always be satisfied. Under standard assumptions on consumer characteristics, condition (i) holds as well and, consequently, a CEFE exists in the general case of pure group externalities of the matching type. MohemkarKheirandish (2001) shows, among other things, that under additional assumptions a CEFE of the form described in the proposition is also a CEFH. He assumes each $U_{i}^{c}$ concave, strictly monotone and continuously differentiable on $\mathbb{R}_{++}^{\ell}$ so that the first order approach applies; each $w_{\{i\}}$ strictly positive; all males of the same type with strict preference for marriage; all females of the same type with strict preference for marriage; an equal number of males and females. Needless to say that a CEFE of the form suggested by Proposition 8 happens to be a $\mathrm{CEFH}$, if the assumptions of Proposition 1 hold. Furthermore, such a CEFE turns out to be a CEFH whenever the strong assumption (ii) of Proposition 2 holds.

However, in general a CEFE of the form described in the last proposition need not be a CEFH. To see this, it suffices to consider a population consisting of one male and one female, where the male has a slight preference (in terms of the utility difference) for staying single and the female has a strong preference for being married. Let the corresponding (absolute) utility differentials be $\epsilon$ for the male and $\Delta$ for the female. Then the stable matching with respect to pure group preferences requires both to remain single. Now suppose they have identical and strictly positive endowments and identical consumption preferences of the Cobb-Douglas type. Then the competitive equilibrium in (i) is a no trade equilibrium. If $\epsilon$ is sufficiently small and $\Delta$ is sufficiently large, they can both benefit from getting married and shifting some consumption from the female to the male - which shows our claim.

Additional examples of non-existence appear in the literature on hedonic coalitions and matching. Example 4 of Bogomolnaia and Jackson (2002), the example of Alkan (1988) and the roommate example of Gale and Shapley (1962) all constitute purely hedonic cases that differ from marriage models. Our Example 5 does not belong to the marriage category either. It shares features of matching and assignment games due to the presence of a consumption good and pure group externalities. Our Example 6 is reminiscent of Example 3.3 in Drèze and Greenberg (1980), despite the fact that the latter is not a marriage model. Their common feature consists in the interaction of household formation and commodity allocation. The striking feature of 
Drèze and Greenberg's example is the absence of externalities. It is driven by household-specific (coalition-specific) endowments $w_{h}$ with $w_{h} \neq \sum_{i \in h} w_{\{i\}}$ for some households $h$.

\subsection{Discussion}

Non-existence of a competitive equilibrium with certain properties renders the discussion of equilibrium household structures and equilibrium welfare obsolete. There are several possible responses to the non-existence problem.

First, the model might be misspecified. For instance, the modeling might be too parsimonious. While household stability cannot be achieved on purely economic grounds, given the two types of outside options depicted here, a full account of all the forces that stabilize - or destabilize - households might restore equilibrium. ${ }^{8}$ Furthermore, the market for marriages may be more competitive than reflected in our equilibrium concept. However, the innovative club-theoretical approach of Ellickson et al. (2001) is plagued with a severe non-existence problem of its own. ${ }^{9}$

Second, one might suspect that price-taking is too restrictive. If only consumers could freely recontract without regard to market prices, then the economy would settle in an equilibrium state in the sense of Edgeworth, that is a core allocation. Indeed, the full core which allows for the reallocation of consumers and commodities, happens to be non-empty in Example 6 . However, Gersbach and Haller (1999) contains a three-person example where gender does not matter and the full core turns out to be empty.

Third, non-existence of equilibrium may capture an important feature of reality. Let us recapitulate the essence of Example 6. Individuals may find it

\footnotetext{
${ }^{8}$ For example, household-specific human capital can serve as a bond among household members, as a referee has pointed out.

${ }^{9}$ Incidentally, in the presence of externalities, a transfer equilibrium à la Ellickson, Grodal, Scotchmer, and Zame need not be Pareto-optimal and need not be a competitive equilibrium with free household formation even when there exist Pareto-optimal competitive equilibria with free household formation. This follows from the extension of an example given in section 5.3 of Gersbach and Haller (2001, pp. 261f). The reason is that in a transfer equilibrium, the transfers within households cannot be renegotiated by members of existing or prospective households. Hence, contrary to what one might be tempted to believe, pricing of household membership does not guarantee elimination of all inefficiencies.
} 
optimal to split at the going market prices in order to reduce negative consumption externalities. But at equilibrium prices of the changed household structure, individuals may find it optimal to form a two-person household in order to benefit from group externalities, because they can buy more of those goods which generate less consumption externalities. The marital status of the woman in the example affects her market opportunities and vice versa. Therefore, the woman may simply go through a sequence of marriage, divorce, marriage, divorce, etc., which constitutes an example of sequential monogamy, possibly with breaks. A dynamic approach suggests itself for future analysis.

Finally, non-existence may simply be a small number or integer problem that goes away when the population is large enough. For instance, nonexistence in Example 5 disappears after suitable replication. Insofar, nonexistence may be considered merely an artifact of the particular example. However, the problem is more intricate. Non-existence in Example 6 does not vanish under replication, not even asymptotically. The reason is that sizeable (relative to the economy) groups of consumers of the same type keep moving simultaneously into or out of households. To end on a positive note, sufficient dispersion of consumer characteristics will restore existence. If each agent is replaced not by identical clones, but by similar yet non-identical copies, then at certain prices, some of the females may wish to remain single while others may wish to stay in two-person households and, consequently, the household structure may end up to be stable. This certainly works in Example 6. This is not to say that existence would never become a problem if only consumer characteristics were well dispersed.

\section{Ramifications and Conclusions}

In this paper, we have studied a general equilibrium model where households operate in a competitive market environment, can have several members and make efficient collective consumption decisions. Our main concern has been the impact (on household stability and equilibrium efficiency) of introducing outside options. Our approach differs from partial equilibrium analysis which has produced countless theoretical and empirical studies of household related issues, involving numerous economic sub-disciplines and touching upon topics as diverse as fertility, mortality, demography, population dynamics, marriage 
and matching, status, income, poverty, nutrition, health, public transfers, intergenerational transfers, education, social capital, human capital, employment, development, welfare, demand and supply, and so forth. Each of the sub-disciplines has developed its own rich body of theories and accumulated a host of empirical work so that even a cursory account would have to be selective. In this section, we shall revisit several of the pertinant issues that arose during the course of our general equilibrium analysis.

\section{1 (In)efficient Household Decisions}

The current investigation is devoted to the allocative consequences of collective rationality, i.e. efficient decisions at the household level. ${ }^{10}$ Since there is evidence for [Horney and McElroy (1988), Browning et al. (1994), Snyder (2000)] and against [Udry (1996)] collective rationality of households, an inquiry into the allocative consequences of inefficient household decisions could be fruitful as well. Compelling evidence that decentralized decision-making within households can be inefficient is provided by Udry (1996) who finds that within Burkina Faso farm households (within certain regions), plots controlled by the women in a household tend to be farmed less intensively than similar plots controlled by the men of the same household. He estimates that about $6 \%$ of output is lost because of inefficient factor allocation within households, assuming decreasing returns to labor inputs. Although household production is not part of our current model, it could conceivably be included. ${ }^{11}$ Udry's findings imply that our model does not readily apply to most of rural Burkina Faso and comparable regions. ${ }^{12}$ Our response to possible inefficiencies at the household level is two-fold.

On the one hand, collective rationality constitutes an important benchmark case and also the most favorable assumption on the local (household level) to

\footnotetext{
${ }^{10}$ Our premise of collective rationality, that each household chooses from its efficient budget set, is very general and leaves a household's exact decision criterion unspecified. Different households may adhere to different criteria. A household may but need not maximize a social welfare function for its members. If it does, it may use endogenously determined welfare weights like in Basu's (1999) "household equilibrium".

${ }^{11}$ Apps and Rees (1997) and Chiappori (1997) incorporate household production into Chiappori's framework of collectively rational households.

${ }^{12}$ In addition, Burkina Faso is far from being the perfect example of a competitive market economy - thus violating another of our fundamental assumptions. For instance, it lacks well functioning labor and agricultural land markets, as Udry reports further.
} 
achieve efficiency at the aggregate level. Insofar, the current inquiry continues and to some extent completes a research program begun by Haller (2000) and further developed in Gersbach and Haller (2001), to investigate the effect of collective rationality of households on general equilibrium outcomes. When the household structure is exogenous so that only two allocation mechanisms, household decisions and competitve exchange interact, then the first welfare theorem frequently holds [Haller (2000)]. If the household structure is endogenous so that household formation interacts with the other two allocation mechanisms, then the first welfare theorem rarely holds, while a version of the second welfare theorem still obtains [Gersbach and Haller (2001)]. In the present paper, we demonstrate that in the presence of externalities, addition of the joining option can destabilize households and equilibrium outcomes and, depending on the particular circumstances, lead to the elimination of inferior, superior, all, or not any equilibria.

On the other hand, we find it equally intriguing to explore the general equilibrium implications of inefficient decision-making by households, in particular since there is evidence for and against the collective rationality property. Suppose some households are making mistakes by the standards of collective rationality. Then one might address the causes of these mistakes or study their allocative consequences. We have given some thought to the second issue in preliminary research on general equilibrium models with inefficient households. Mistakes at the household level introduce a bias towards inefficient equilibrium outcomes. Moreover, giving up the collective rationality postulate amounts to working with fewer structural restrictions, unless the postulate is replaced by a plausible alternative. For these two reasons, it appears prima facie difficult to draw any more specific conclusions after giving up collective rationality. Yet it turns out that detailed analysis of many important features of the model can still be performed. To give a flavor of the analysis, we may conveniently pretend that the household follows a twostep procedure, although it makes only a single decision to pick a point in its budget set. First, it determines its net trade with the market. In the second step, after executing its net trade with the market, the household distributes its available resources among its members. If the household makes a mistake in the first step (without a mistake in the second), then the resulting allocation may still be Pareto-optimal, since undoing the household's mistake would require altering the net trades of other households as well which may be impossible without making some member of some other household worse 
off. If the household makes a mistake in the second step (with or without a mistake in the first step), then a weak Pareto improvement is posssible, since household members can be made better off without making individuals outside the household worse off. For details and examples, we refer to Gersbach and Haller (2002).

Instead of concentrating on particular consequences of inefficient household decisions, one may ask if and how the broader conclusions of the current paper would be affected by a relaxation of the collective rationality postulate. First of all, outside options can serve a disciplinary function and foster efficient household decisions. Namely, suppose that only multi-member households may conceivably make mistakes because of frictions in the group decision process whereas single households never make mistakes. Suppose also absence of externalities. Then household decisions are necessarily efficient in any competitive equilibrium with free exit. ${ }^{13}$ Hence, as we show in Gersbach and Haller (2002), the neutrality theorem not only persists, but can be strengthened when inefficiencies are admitted.

The result implies that (the degree of) inefficiency is not merely an inherent property of the household, but is to some extent an endogenous phenomenon and depends on the conditions under which the household operates. This observation applies immediately to the case of inefficiency reported by Udry (1996). Inefficient factor allocation within the household is the kind of mistake that can be rectified at the household level and, therefore, gives rise to a sub-optimal allocation for the economy. Together with other causes e.g. acquisition and preservation of land property rights through cultivation; non-contractible intra-household allocations - a lock-in situation for married women, that is a lack of outside options can be one of the causes that help perpetuate those inefficiencies.

In the concrete case of Burkina Faso family farm households, more output can be produced with the same amounts of factor inputs, a clear efficiency gain. Notice, though, that from a general equilibrium perspective, eventual local (household) efficiency gains need not necessarily translate into local welfare gains. An increase of total resources certainly enhances some consumers' welfare. However, an increase in agricultural output across many farm households can put downward pressure on prices for agricultural pro-

\footnotetext{
${ }^{13}$ In the presence of externalities, outside options tend to play a less drastic role as a disciplinary device, but remain effective in many instances.
} 
duce with the result that some or most of the benefits from the efficiency gains accrue to non-farm households. In the extreme, the efficiency gains in those farm households could be detrimental to them, like in Bhagwati's (1958) immiserizing growth.

In addition to the insight that the exit option can induce collective rationality in equilibrium, a strengthening of the neutrality theorem, other major propositions of the present paper remain intact if the collective rationality assumption is relaxed. For example, we found in subsection 4.2 that availability of the exit option does not prevent coexistence of Pareto-rankable equilibria. This finding is not limited to the case of collectively rational households. Likewise, our general observations about the overall effect of adding the joining option to the exit option hold with and without collective rationality of households: Depending on the particular circumstances, inferior, superior, all or no CEFE are eliminated.

\subsection{Theory and Evidence}

Though ours is a purely theoretical investigation, it has been motivated by prior empirical work on household decisions. In this subsection, we relate our analysis to past empirical findings and potential future empirical studies. Since our model encompasses three interacting allocation mechanisms (household formation, household decisions, competitive exchange among households), testing the model in its entirety could prove to be a formidable task. But particular aspects of the model have been or might be tested. To be more specific, let us consider each of the three allocation mechanisms separately, beginning with decision-making by households.

The central assumption of our model is collective rationality of households in the sense of Chiappori (1988a, 1992), in contrast to the traditional unitary or representative consumer model of the household. Using National Longitudinal Surveys (NLS) data and a parametrized Nash bargaining model of household behavior, Horney and McElroy (1988) conclude that the specific collective rationality model performs better than the unitary model. Using Canadian family expenditure data and parametric methods, Browning et al. (1994) find that the collective rationality restrictions cannot be rejected while the unitary model restrictions are rejected. Chiappori (1988a) derives restrictions on household-level data and individual labor supplies that pro- 
vide necessary and sufficient conditions for consistency with the collective rationality model. Adapting the techniques of Brown and Matzkin (1996), Snyder (2000) derives a set of equivalent conditions. In addition, she considers the analogue for the unitary model and applies those nonparametric tests to a sample from the NLS for men. She finds that all 265 households satisfy the restrictions of the collective rationality model whereas 259 of them satisfy the restrictions of the unitary model. Replication with a sample from the NLS for mature women resulted in all 108 households passing the collective rationality test and 4 failing the unitary test. ${ }^{14}$ We already mentioned in footnote 1 that Chiappori, Fortin and Lacroix (2002) find a sizeable impact of a "divorce laws index" on the intra-household decision process which can be viewed as evidence for the importance of the exit option for intra-household allocation.

Let us now turn to household formation. Most of the empirical research has focused on variants of the Becker (1973) model, in part because of its prominence, in part because of its quantitative predictions. Suen and Lui (1999) consider a sample from the Hong Kong marriage market and go beyond the ususal practice to tabulate (correlate) female characteristics against (with) male characteristics in the observed matchings. Rather they exploit the full matrix of potential couples in the market and the fact that two people could, but chose not to marry each other conveys information about the underlying production function of marital output. They use a computer algorithm to solve the optimal assignment problem. Comparison of the computed optimal matching and the observed matching allows them to assess the efficient market hypothesis of Becker, that competition for spouses leads to a matching that maximizes the sum of marital outputs. Suen and Liu conclude that the Hong Kong marriage market is not grossly inefficient, ignoring by and large both the external conditions (commodity market conditions) and the internal conditions (intra-household bargaining) under which households operate.

Let us turn next to competitive exchange in a general equilibrium setting. A long-standing criticism of general equilibrium theory relates to its presumed lack of empirical content. Indeed, parametric tests of the model per se have

\footnotetext{
${ }^{14}$ We should mention that the appropriate modelling and testing of non-unitary household behavior is not without controversy; see the debate between McElroy and Horney (1981, 1990) claiming generality of the Nash-bargaining approach and Chiappori (1988b, 1991) disputing it. Notice also important differences between the nonparametric tests employed by Brown and Matzkin, Snyder and others and the standard parametric approach.
} 
no bite, since the general theory is based on a parameter-free description of preferences. Brown and Matzkin (1996) were the first to demonstrate, by means of a two-consumer two-good example, that the theory is testable if the data consist of finitely many observations of individual endowments and market clearing prices. This much acclaimed result put the criticism to a halt, but did not put it to rest. Snyder (2001) shows that if the number of consumers is larger than or equal to the number of goods, then there are no restrictions on finite data sets consisting of total resources and equilibrium prices — where equilibrium prices are associated with some distribution of individual endowments compatible with the total resources. ${ }^{15}$ What is observable turns out to be crucial for the testability of general equilibrium models.

Finally, let us identify two specific and crucial aspects of our model that could possibly be tested. First, the Neutrality Theorem (Proposition 1) essentially states that in the absence of externalities, household formation does not have any allocative and welfare consequences. Therefore, it would be desirable to test for household-specific externalities and especially for household-specific public goods, for instance complementarity in leisure consumption. A comparison of Snyder (1999) and Snyder (2000) suggests that the nonparametric restrictions will be different for households with and without a householdspecific public good. Therefore, it is testable whether household-specific public goods are present.

Secondly, we study the effect of outside options on household formation, household stability, equilibrium existence, and equilibrium efficiency and find that the addition of JO, the joining option, can destabilize the household structure and undo certain equilibria. In our model, the value of an outside option is dependent on relative prices and the prevailing household structure. This endogeneity makes it difficult to identify threat points in households empirically as the literature surveyed by Bourguignon and Chiappori (1994) suggests. But instead of focusing on the household level, one could possibly look at society at large. The Roman Catholic church, as a rule, prohibits remarriage of divorcees. Consequently, JO was de facto unavailable in pri-

\footnotetext{
${ }^{15}$ Snyder (2001) further finds that the theory is testable if the distribution of income is taken as exogenously given. Balasko and Tvede (2002) show that when total resources are kept constant or constrained to remain collinear, no further restrictions apply to equilibrium data sets, a conclusion which does not require an assumption on the relative number of consumers and goods and is robust to small perturbations of the total resources.
} 
marily Catholic countries until civil marriage alone or cohabitation without marriage became acceptable, legal, or tolerated. Our results suggest the hypothesis that the sudden availability of the joining option would have a substantial impact on divorce rates. This hypothesis can be tested for countries which experienced a change of attitude towards remarriage, without a change of divorce law during the same time period. If, moreover, one is willing to parametrize preferences in a specific form such as (11), then the model would predict which households might dissolve and even which household members would seek a divorce.

\subsection{Future Extensions and Public Policy Analysis}

While our primary focus was to develop a basic framework to study the allocation of commodities and individuals, suitable extensions may be of use for public policy analysis. Public policy issues in at least three areas might be addressed within the current framework. The first area consists of policies that directly affect outside options. The second area comprises policies that influence consumption externalities. The last category includes taxes and transfers to and from households and their members. Let us illustrate potential applications in each area by specific examples.

To begin with the first area, laws governing the right to divorce, child support and marital property upon divorce influence directly the attractiveness of exercising outside options. Since we have found no efficiency reducing effect arising from the availability of the exit option, our results tend to support unilateral divorce laws specifying that either spouse can initiate divorce without forgoing his or her property rights. By contrast, mutual-consent laws that require either agreement of both spouses or proof of marital fault are not supported by our results. There remains the intriguing question whether legal claims against an ex-spouse should depend on the marital or household status of the beneficiary, as is the case in many countries. In a broader sense, should the allocation of property rights (alimony, entitlement to retirement benefits, division of jointly owned assets) between ex-spouses depend on who of the two takes the exit option and who takes the joining option?

A special study devoted to the effects of the joining option could help answer this question. Suppose future research shows that, as a rule, granting more outside options to individuals promotes social efficiency. Then divorce- 
related property rights should not depend on the presence of other adults in the new households of the ex-spouses. However, some of our examples suggest that the joining option tends to destabilize households and to eliminate superior equilibria. If these negative effects turn out to be the rule, then taking the joining option should possibly be discouraged, for instance by granting less generous property rights to those who exercise it. Under a discriminatory policy, the transfer would depend, among other things, on whether the former wife forms a household with a new partner or not. Stability of households would seem a more pressing issue when children are involved, who depend on parents and have no outside options of their own. If adults do not completely internalize the future well-being of their offspring when dissolving households and forming new ones, then divorce and tax laws might provide incentives to improve the welfare of children. A more comprehensive model could include children and allow us to examine to what extent legal provisions for the sake of children have the intended impact.

Secondly, taxes that can affect consumption externalities may also affect the stability of households. Consider a two-person household which is formed because of positive group externalities. But one non-smoking member suffers from negative consumption externalities, because the partner is smoking. A sufficiently large cigarette tax reduces smoking and, depending on the elasticity of cigarette demand, may increase or reduce consumption of the remaining goods in the household. In the former case, a cigarette tax can enhance the stability of the particular household — which might serve as an additional argument in support of such a "sin tax". In the latter case, there is less disposable income for other consumption goods. It may fall to a point where the non-smoker suffers a significant reduction of consumption. If the loss in consumption is insufficiently compensated by the reduced externality, then the non-smoker might prefer to leave the household. Thus a heavy "sin tax" may destabilize certain households, if the tax burden gets shifted towards the non-targeted household member(s). More generally, we can address questions of tax incidence which an approach based on the unitary model of the household is bound to miss.

Finally, most tax and benefit policies impact on the incomes and the marginal wages of all workers in a household. Consider the case of female labor supply. A sizeable fraction of women do not work outside of their home when living with partners, but presumably would go to work if they were single unless they went on welfare instead. Whether or not such corner solutions 
occur depends among other things on household decisions regarding care for children but very likely also on how a second household income is treated with respect to taxation and transfers. High marginal tax rates on second household incomes occur naturally when taxation is progressive, only total household income is taxed and tax codes do not distinguish between multiperson and single-person households. Such tax systems tend to promote the aforementioned corner solutions. They may also make the exit option excessively attractive, conceivably with undesirable consequences. Hence they can influence both the allocation of resources and the composition of households. Yet abolishing the so-called "marriage penalty" may simply provide a windfall to working couples, without a fundamental change in household composition or female labor market participation. ${ }^{16}$ A general equilibrium model like ours, with multi-member households and household formation, augmented with a production sector and labor markets, can help sort out the intricate implications of such tax policy decisions. Compared to partial analysis, the suggested approach has the advantage that it not only captures individual responses, but also the market reaction to a change in tax law.

Irrespective of potential policy implications, our framework is also well suited to explain sociological trends, for example an increase of singles in the population. An investigation of such a trend could differentiate between several causes and take into account how different outside options affect spatial mobility and exploitation of job market opportunities in different ways. Last, not least the important issue remains how resources are shared among household members. That brings us back to the origins of the collective rationality approach, one of the main justifications of which is, after all, the possibility of investigating the intra-household allocation of resources. So far, we have mainly studied the global impact of outside options, on stability and efficiency of household structures and commodity allocations. One might examine the local impact of outside options instead, for instance the effect of an additional outside option on the intra-household distribution of welfare when the global impact is moderate, that is when the household structure remains intact and the induced price changes are minor. Who in the household would gain? In general, the answer to this question is not straightforward because

\footnotetext{
${ }^{16}$ A number of countries, including Germany and the United States, strictly speaking do not have a mandatory "marriage penalty", since they allow separate filing or "tax splitting" by married couples which, however, is more complicated and time consuming than joint filing.
} 
an added outside option tends to increase the utility level a member has to obtain in order to stay in the household - which in turn would reduce the surplus available to other members. Thus an added outside option tends to raise the minimum utility level a household member has to be guaranteed and to lower the maximum utility level the household member can achieve. In the absence of externalities the answer is given by Proposition 1 and Example 1: With exit option, the lower and the upper bound for a household member's utility coincide, zero surplus remains to be shared and nobody can gain or lose from being a member of a multi-person household. Adding the joining option has no further effect. We have also analyzed an example with positive externalities and a real effect of adding the joining option. But more systematic work needs to be done. 


\section{Appendix}

\section{Proof of Proposition 1:}

Step 1:

We show that $(p, \mathbf{x} ; P)$ is a competitive equilibrium with free exit if and only if $\left(p, \mathbf{x} ; P^{0}\right)$ is a competitive equilibrium with free exit where $P^{0}=\{\{i\}: i \in I\}$.

Suppose now that $\left(p, \mathbf{x} ; P^{0}\right)$ is a CEFE. Recall that absence of externalities and local non-satiation is assumed. Hence, by the first welfare theorem, $\mathbf{x}$ is Pareto-optimal — regardless of the household structure. We claim that

$$
\mathbf{x}_{\mathbf{h}} \in E B_{h}(p) \text { for any potential household } h .
$$

Clearly, $p x_{i} \leq p \omega_{i}$ for all $i$, hence $p * \mathbf{x}_{\mathbf{h}} \leq p \omega_{h}$, i.e. $\mathbf{x}_{\mathbf{h}} \in B_{h}(p)$ for all potential households $h$. Suppose $\mathbf{x}_{\mathbf{h}} \notin E B_{h}(p)$ for some $h$. Then there exists $\mathbf{y}_{\mathbf{h}} \in B_{h}(p)$ with

$$
\begin{aligned}
& U_{i}\left(y_{i}\right) \geq U_{i}\left(x_{i}\right) \text { for all } i \in h \\
& U_{j}\left(y_{j}\right)>U_{j}\left(x_{j}\right) \text { for some } j \in h .
\end{aligned}
$$

Equilibrium and local non-satiation imply

$$
\begin{aligned}
& p y_{i} \geq p \omega_{i} \text { for all } i \in h ; \\
& p y_{j}>p \omega_{j} \text { for some } j \in h .
\end{aligned}
$$

Hence $p * \mathbf{y}_{\mathbf{h}}>p \omega_{h}$, contradicting $\mathbf{y}_{\mathbf{h}} \in B_{h}(p)$. Therefore, (17) has to hold which implies the first condition of a competitive equilibrium with free exit. Further observe that the second and third defining conditions of a competitive equilibrium with free exit are trivially met here. Hence $(p, \mathbf{x} ; P)$ is a CEFE.

Suppose next that $(p, \mathbf{x} ; P)$ is a competitive equilibrium with free exit. Because of local non-satiation, $p \gg 0$. Because of continuity, we can then choose for each $i \in I$ a utility maximizer $x_{i}^{0}$ in $B_{\{i\}}(p)$, pertaining to the event that consumer $i$ is acting individually and trading from his endowment $\omega_{i}$ at prices $p$. Since $(p, \mathbf{x} ; P)$ is a CEFE,

$$
U_{i}\left(x_{i}\right) \geq U_{i}\left(x_{i}^{0}\right) \text { for all } i \in I .
$$

We claim that

$$
U_{i}\left(x_{i}\right)=U_{i}\left(x_{i}^{0}\right) \text { for all } i \in I \text {. }
$$


Suppose not. Then there exists a household $h \in P$ such that

$$
\begin{aligned}
U_{i}\left(x_{i}\right) & \geq U_{i}\left(x_{i}^{0}\right) \text { for all } i \in h, \\
U_{j}\left(x_{j}\right) & >U_{j}\left(x_{j}^{0}\right) \text { for some } j \in h .
\end{aligned}
$$

Hence, some individuals $j \in h$ cannot afford $x_{j}$ when trading from $\omega_{j}$ at prices $p$. Hence, $p \cdot x_{j}>p \cdot \omega_{j}$. For all individuals $i$ we have $p \cdot x_{i} \geq p \cdot \omega_{i}$. Summing up all individual budget constraints yields

$$
p * \mathbf{x}_{h}=p \cdot\left(\sum_{i \in h} x_{i}\right)>p \cdot\left(\sum_{i \in h} \omega_{i}\right)=p \cdot \omega_{h}
$$

which, however, violates the budget constraint of household $h$. Hence, $U_{i}\left(x_{i}\right)=$ $U_{i}\left(x_{i}^{0}\right), i \in I$. Because of local non-satiation, (18) implies

$$
p x_{i} \geq p x_{i}^{0}=p \omega_{i} \text { for all individuals } i .
$$

We further claim that

$$
x_{i} \in B_{\{i\}}(p) \text { for all } i \in I .
$$

Suppose not. Then there exists a household $h \in P$ such that

$$
\begin{array}{r}
p x_{i} \geq p \omega_{i} \text { for all } i \in h, \\
p x_{j}>p \omega_{j} \text { for some } j \in h,
\end{array}
$$

leading once more to a violation of the household's budget constraint. Hence (19) must hold. (18) and (19) imply that $\left(p, \mathbf{x} ; P^{0}\right)$ is a CEFE.

Step 2:

We show that if $\left(p, \mathbf{x} ; P^{0}\right)$ is a competitive equilibrium with free exit where $P^{0}=\{\{i\}: i \in I\}$, then for any $P \in \mathcal{P},(p, \mathbf{x} ; P)$ is also a competitive equilibrium with free household formation.

Now let $\left(p, \mathbf{x} ; P^{0}\right)$ be a CEFE and $P$ be any feasible household structure. Because of the absence of externalities and local non-satiation, the first welfare theorem applies and $\mathbf{x}$ is Pareto-optimal regardless of the household structure. From step 1 we know that $(p, \mathbf{x} ; P)$ is a CEFE and

$$
\mathbf{x}_{\mathbf{h}} \in E B_{h}(p) \text { for any potential household } h .
$$


We want to show that $(p, \mathbf{x} ; P)$ is also a CEFH. Suppose not. Hence, there exist two households $g$ and $h$ in $P$ and $i \in h$ and a consumption allocation $\mathbf{y}_{\mathbf{g} \cup\{\mathbf{i}\}}$ in $B_{g \cup\{i\}}(p)$ such that

$$
\begin{aligned}
& U_{i}\left(y_{i}\right)>U_{i}\left(x_{i}\right) \text { and } \\
& U_{j}\left(y_{j}\right) \geq U_{j}\left(x_{j}\right) \text { for all } j \in g .
\end{aligned}
$$

Local non-satiation implies

$$
\begin{aligned}
& p y_{i}>p \omega_{i}=p x_{i} \text { and } \\
& p y_{j} \geq p \omega_{j}=p x_{j} \text { for all } j \in g .
\end{aligned}
$$

Hence, individual $i$ cannot afford $y_{i}$ when trading from $\omega_{i}$ at prices $p$. For all individuals $j \in g$ we have $p \cdot x_{j} \geq p \cdot \omega_{j}$. Summing up all individual budget constraints yields

$$
p * \mathbf{y}_{\mathbf{g} \cup\{\mathbf{i}\}}=p \cdot y_{i}+p \cdot \sum_{j \in g} x_{j}>p \cdot \omega_{i}+p \cdot \sum_{j \in g} \omega_{j}=p \cdot \omega_{g}+p \cdot \omega_{i}
$$

which, however, violates the budget constraint of household $g \cup\{i\}$.

Hence, we obtain a contradiction unless $(p, \mathbf{x} ; P)$ is a CEFH. Q.E.D.

\section{Proof of Proposition 2:}

Suppose the state $(p, \mathbf{x} ; P)$ satisfies (i) and (ii). For $i \in I$, let $P(i)$ denote the element of $P$ to which $i$ belongs. We claim that there do not exist any $i \in I$ and $h \in \mathcal{H}_{i}$ with $U_{i}^{g}(h)>U_{i}^{g}(P(i))$. For otherwise, there would exist an optimal household structure based solely on group preferences, $P^{*}$ such that $U_{i}^{g}\left(P^{*}(i)\right) \geq U_{i}^{g}(h)>U_{i}^{g}(P(i))$ and, therefore, $P^{*} \neq P$, contradicting (ii). Moreover, we observe that $\mathbf{x}$ is a Pareto-optimal allocation of the pure exchange economy $\left(U_{i}^{c}, \omega_{\{i\}}\right)_{i \in I}$.

Consider now any feasible allocation $\left(\mathbf{y} ; P^{\prime}\right)$ and $i \in I$. Suppose $U_{i}\left(\mathbf{y}_{\mathbf{P}^{\prime}(\mathbf{i})} ; P^{\prime}(i)\right)>U_{i}\left(\mathbf{x}_{\mathbf{P}(\mathbf{i})} ; P(i)\right)$. Then we claim that $U_{j}\left(\mathbf{y}_{\mathbf{P}^{\prime}(\mathbf{j})} ; P^{\prime}(j)\right)<$ $U_{j}\left(\mathbf{x}_{\mathbf{P}(\mathbf{j})} ; P(j)\right)$ for some $j \in I$. Namely, $U_{i}^{g}\left(P^{\prime}(i)\right) \leq U_{i}^{g}(P(i))$. Hence $U_{i}^{c}\left(y_{i}\right)>U_{i}^{c}\left(x_{i}\right)$. This implies $U_{j}^{c}\left(y_{j}\right)<U_{j}^{c}\left(x_{j}\right)$ for some $j \in I$, since $\mathbf{x}$ 
is a Pareto-optimal allocation of the pure exchange economy $\left(U_{i}^{c}, \omega_{\{i\}}\right)_{i \in I}$. Further $U_{j}^{g}\left(P^{\prime}(j)\right) \leq U_{j}^{g}(P(j))$. Hence the claim. This shows that the allocation $(\mathbf{x} ; P)$ is fully Pareto-optimal.

Next we prove that the state $(p, \mathbf{x} ; P)$ is a competitive equilibrium with free household formation. Suppose not. Hence, there exist a household $h \in P$ and an individual $i \in h$ such that either $i$ is better off as a single or there exists a household $g \in P$ which $i$ can join and where the utility of all members of the newly created household $g \cup\{i\}$ can be improved. We concentrate on the latter case. The case when individual $i$ forms a one-person household is similar.

Let $\mathbf{y}_{\mathbf{g} \cup\{\mathbf{i}\}} \in B_{g \cup\{i\}}(p)$ be an allocation in the newly created household $g \cup\{i\}$ which makes everybody in this household better off. Since $U_{j}^{g}(g \cup\{i\}) \leq$ $U_{j}^{g}(P(j)), U_{j}^{c}\left(y_{j}\right)>U_{j}^{c}\left(x_{j}\right)$ has to hold for each $j \in g \cup\{i\}$. But since $(p, \mathbf{x})$ is a competitive equilibrium of the pure exchange economy $\left(U_{i}^{c}, \omega_{\{i\}}\right)_{i \in I}$, this implies $p y_{j}>p \omega_{j}$ for all $j \in g \cup\{i\}$. Therefore, $p * \mathbf{y}_{\mathbf{g} \cup\{\mathbf{i}\}}>p \cdot \omega_{g \cup\{i\}}$, contradicting $\mathbf{y}_{\mathbf{g} \cup\{\mathbf{i}\}} \in B_{g \cup\{i\}}(p)$. Q.E.D.

\section{Proof of Proposition 4:}

We start from the proof of Proposition 1 in Gersbach and Haller (1999) and introduce exit options. By (iv), we can choose a potential household $h \in \mathcal{H}$ with $1<|h|<n$ and large group advantage. Let us choose such a household $h$ and corresponding $\delta_{i}(p),(i, p) \in h \times \Delta^{0}$, and $X_{h}(p), p \in \Delta$, with the properties stipulated by LGA. Consider the household structure

$$
\bar{P}=\{h\} \bigcup\{\{i\}: i \notin h\} \text {. }
$$

We claim that there exists a competitive equilibrium with free exit $(p, \mathbf{x} ; \bar{P})$. In the following we take the desired household structure $\bar{P}$ as given. It remains to show the existence of a pair $(p, \mathbf{x})$ so that $(p, \mathbf{x} ; \bar{P})$ constitutes a competitive equilibrium with free exit. A first crucial step in the argument is to show that with suitably chosen reduced budget sets the resulting market excess demand relation is non-empty-valued, convex-valued, u.h.c., and satisfies the strong form of Walras' law. In a second step, we obtain a market clearing price system $p \in \Delta^{o}$ and a respective feasible allocation $\mathbf{x}$ for the hypothetical economy with reduced budget sets. In a final step, we are going to show that, indeed, $(p, \mathbf{x} ; \bar{P})$ is a competitive equilibrium with free exit.

Step 1. We consider household $h$ maximizing, for each $p \in \Delta$, its aggregate 
welfare $W_{h}$ defined as

$$
W_{h}\left(\mathbf{x}_{\mathbf{h}}\right)=\sum_{i \in h} U_{i}\left(\mathbf{x}_{\mathbf{h}} ; h\right)
$$

on its restricted budget set $X_{h}(p)$. Because of LGA, $X_{h}(p)$ is convex, compact and non-empty. $W_{h}$ is continuous and concave. Hence the set of aggregate welfare maximizers is non-empty, convex and compact. Consequently $D_{h}(p)$, the household's aggregate demand set, is non-empty, convex and compact. Moreover, the constraint correspondence $X_{h}(\cdot)$ is continuous. Therefore, by the Maximum Theorem (Ellickson (1993; Th. 5.47)), the demand correspondence $D_{h}(\cdot)$ is u.h.c.

For each one-person household $\{i\}, i \notin h$, let the household maximize, for each $p \in \Delta$, its utility $U_{i}\left(x_{i} ;\{i\}\right)$ on the truncated budget set $B_{\{i\}}(p) \cap K$ which is non-empty, convex and compact. Hence $D_{\{i\}}(p)$, the set of utility maximizers is non-empty, convex and compact. Since $\omega_{i} \gg 0$, the constraint correspondence $B_{\{i\}}(\cdot) \cap K$ is continuous. Again by the Maximum Theorem (Ellickson (1993; Th. 5.47)), the demand correspondence $D_{\{i\}}(\cdot)$ is u.h.c.

For household $h$, the presence of a consumer $j \in h$ whose preferences are strictly monotonic in his own consumption and who does not impose any negative externalities on other household members, implies budget exhaustion. For all consumers $i \notin h$, strict monotonicity of preferences implies budget exhaustion by household $\{i\}$.

Aggregation across households in $\bar{P}$ yields that $\Phi(\cdot)$, the market excess demand relation resulting from reduced budget sets is non-empty-valued, convex-valued, u.h.c., and satisfies the strong form of Walras' law.

Step 2. By Theorem 6.37 of Ellickson (1993), there exists a pair $(p, \mathbf{z}) \in$ $\Delta \times \mathbb{R}^{\ell}$ with

(a) $\mathbf{z} \in \Phi(p)$ and

(b) $\mathbf{z} \leq 0$ and $\mathbf{z}=0$ whenever $p \gg 0$.

Condition (a) means that

$$
\mathbf{z}=\sum_{g \in \bar{P}} \mathbf{d}_{\mathbf{g}}-\omega_{S}
$$

where $\mathbf{d}_{\mathbf{g}} \in D_{g}(p)$ for each $g \in \bar{P}$. A standard argument shows that for each $i \notin h$, if $\mathbf{d}_{\{i\}}$ maximizes $i$ 's utility on the truncated budget set $B_{\{i\}}(p) \cap K$, 
then it is also a utility maximizer on the non-truncated budget set $B_{\{i\}}(p)$. But then strict monotonicity of $i$ 's preferences requires $p \gg 0$. By assumption, $\bar{P}$ admits at least one single-person household. Therefore, by condition (b), $\mathbf{z}=0$. Let us write $x_{i}$ for $\mathbf{d}_{\{\mathbf{i}\}}$ from now on.

Step 3. It remains to deal with household $h$. By definition, we have $\mathbf{d}_{\mathbf{h}}=$ $\sum_{i \in h} x_{i}$ where $\mathbf{x}_{\mathbf{h}}=\left(x_{i}\right)_{i \in h}$ maximizes $W_{h}$ on $X_{h}(p)$. We have to show that $\mathbf{x}_{\mathbf{h}}$ is an efficient collective choice of household $h$ under its budget constraint, i.e. $\mathbf{x}_{\mathbf{h}} \in E B_{h}(p)$, and that nobody wants to leave the household at the going prices.

Maximizing $W_{h}$ on $X_{h}(p)$ is the same as maximizing $W_{h}$ on $B_{h}(p) \cap K^{h}$, subject to the additional constraint (3) for all $i \in h$. We claim that if $\mathbf{x}_{\mathbf{h}}$ maximizes $W_{h}$ on $B_{h}(p) \cap K^{h}$ subject to the constraints (3), then $\mathbf{x}_{\mathbf{h}}$ is an efficient collective choice of household $h$ with respect to the truncated budget set $B_{h}(p) \cap K^{h}$, without further qualifications. Namely, for some consumer in $h$ to do better at $\mathbf{y}_{\mathbf{h}} \in B_{h}(p) \cap K^{h}$ than at $\mathbf{x}_{\mathbf{h}}$ without making anybody else in $h$ worse off, would increase the value of $W_{h}$ and, hence, would require $\mathbf{y}_{\mathbf{h}} \notin X_{h}(p)$. But then by LGA, there is some other consumer $i$ in $h$ who violates (3) at $\mathbf{y}_{\mathbf{h}}$ and, therefore, is worse off at $\mathbf{y}_{\mathbf{h}}$ than at $\mathbf{x}_{\mathbf{h}}$, a contradiction.

After having shown that $\mathbf{x}_{\mathbf{h}}$ is an efficient collective choice of household $h$ with respect to the truncated budget set $B_{h}(p) \cap K^{h}$, we claim next $\mathbf{x}_{\mathbf{h}} \in$ $E B_{h}(p)$. This follows from a routine argument as in the case of single-person households. We finally claim that no household member has an incentive to leave at the going prices. But this follows immediately from the fact that $\mathbf{x}_{\mathbf{h}} \in X_{h}(p)$. For the latter fact implies that each household member $i$ satisfies (3) and thus $U_{i}\left(\mathbf{x}_{\mathbf{h}} ; h\right) \geq U_{i}\left(x_{i}^{0}(p) ;\{i\}\right)$ for all $i \in h$. Hence, no individual wants to exit household $h$ and $(p, \mathbf{x} ; \bar{P})$ is a competitive equilibrium with free exit as asserted. Q.E.D. 


\section{References}

Alkan, A. (1988): "Nonexistence of Stable Threesome Matchings: Note", Mathematical Social Sciences, 16, 201-209.

Alkan, A. and D. Gale (1990): "The Core of the Matching Game", Games and Economic Behavior, 2, 203-212.

Apps, P.F. and R. Rees (1997): "Collective Labor Supply and Household Production", Journal of Political Economy, 105, 178-190.

Balasko, Y. and M. Tvede (2002): "The Geometry of Finite Equilibrium Data Sets," CERAS, Geneva, and Institute of Economics, University of Copenhagen.

Banerjee, S., Konishi, H. and T. Sönmez (2001): "Core in a Simple Coalition Formation Game", Social Choice and Welfare, 18, 135-153.

Basu, K. (1999): "Child Labor: Cause, Consequence and Cure, with Remarks on International Labor Standards", Journal of Economic Literature, 37, 1083-1119.

Becker, G.S. (1973): "A Theory of Marriage, Part I," Journal of Political Economy, 81, 813-846. Reproduced as Chapter 11 in R. Febrero and P.S. Schwartz (eds): The Essence of Becker, Hoover Institution Press, Stanford, CA, 1995.

Bennett, E. (1988): "Consistent Bargaining Conjectures in Marriage and Matching", Journal of Economic Theory, 45, 392-407.

Bennett, E. (1997): "Multilateral Bargaining Problem", Games and Economic Behavior, 19, 151-179.

Bhagwati, J. (1958): "Immiserizing Growth: A Geometrical Note," Review of Economic Studies, 25, 201-205.

Bogomolnaia, A. and M.O. Jackson (2002): "The Stability of Hedonic Coalition Structures", Games and Economic Behavior, 38, 201-230.

Bourguignon, F. and P.-A. Chiappori (1994): "The Collective Approach to Household Behaviour," in R. Blundell, I. Preston, and I. Walker (eds.): The Measurement of Household Welfare, Cambridge University Press. 
Brown, D.J. and R. L. Matzkin (1996): "Testable Restrictions on the Equilibrium Manifold," Econometrica, 64, 1249-1262.

Browning, M., Bourguignon, F., Chiappori, P.-A., and V. Lechene (1994): "Incomes and Outcomes: A Structural Model of Intra-Household Allocation", Journal of Political Economy, 102, 1067-1096.

Chiappori, P.-A. (1988a): "Rational Household Labor Supply," Econometrica, 56, 63-89.

Chiappori, P.-A.: "Nash-Bargained Household Decisions: A Comment," International Economic Review 29, (1988b), 791-796.

Chiappori, P.-A.: "Nash-Bargained Household Decisions: A Rejoinder," International Economic Review 32 (1991), 761-762.

Chiappori, P.-A. (1992): "Collective Labor Supply and Welfare," Journal of Political Economy, 100, 437-467.

Chiappori, P.-A. (1997): "Introducing Household Production in Collective Models of Labor Supply", Journal of Political Economy, 105, 191-209.

Chiappori, P.-A., B. Fortin and G. Lacroix (2002): "Marriage Market, Divorce Legislation, and Household Labor Supply", Journal of Political Economy, 110, 37-72.

Crawford, V.P. and S.C. Rochford (1986): "Bargaining and Competition in Matching Markets", International Economic Review, 27, 329-348.

Drèze, J. and J. Greenberg (1980): "Hedonic Coalitions: Optimality and Stability", Econometrica, 48, 987-1003.

Debreu, G. (1952): "A Social Equilibrium Existence Theorem", Proceedings of the National Academy of Sciences of the U.S.A., 38, 886-893.

Ellickson, B. (1993): Competitive Equilibrium. Cambridge University Press.

Ellickson, B., Grodal, B., Scotchmer, S., and W.R. Zame (1999): "Clubs and the Market", Econometrica, 67, 1185-1218.

Ellickson, B., Grodal, B., Scotchmer, S., and W.R. Zame (2001): "Clubs and the Market: Large Finite Economies", Journal of Economic Theory, 101, 40-77. 
Gale, D. (1984): "Equilibrium in a Discrete Exchange Economy with Money", International Journal of Game Theory, 13, 61-64.

Gale, D. and L. Shapley (1962): "College Admissions and the Stability of Marriage", American Mathematical Monthly, 92, 261-268.

Gersbach, H. and H. Haller (1999): "Allocation Among Multi-Member Households: Issues, Cores and Equilibria," in A. Alkan, C.D. Aliprantis and N.C. Yannelis (eds.): Current Trends in Economics: Theory and Applications. Springer-Verlag: Berlin/Heidelberg.

Gersbach, H. and H. Haller (2001): "Collective Decisions and Competitive Markets," Review of Economic Studies, 68, 347-368.

Gersbach, H. and H. Haller (2002): "When Inefficiency Begets Efficiency", Department of Economics, Virginia Polytechnic Institute and State University, Blacksburg, VA.

Greenberg, J. (1978): "Pure and Local Public Goods: a Game-theoretic Approach", in A. Sandmo (ed.): Essays in Public Economics, Lexington, MA: Heath and Co.

Haller, H. (2000): "Household Decisions and Equilibrium Efficiency", International Economic Review, 41, 835-847.

Hirschman, A.O. (1970): "Exit, Voice, and Loyalty", Harvard University Press, Cambridge, Massachusetts.

Horney, M.J. and M.B. McElroy (1988): "The Household Allocation Problem: Empirical Results from a Bargaining Model", Research in Population Economics, 6, 15-38.

Jehiel, P. and S. Scotchmer (2001): "Constitutional Rules of Exclusion in Jurisdiction Formation", Review of Economic Studies, 68, 393-411.

Mas-Collell, A., Whinston, M.D., and J.R. Green (1995): Microeconomic Theory. Oxford University Press.

Mohemkar-Kheirandish, R. (2001): "Gains and Losses from Household Formation", Department of Economics, Virginia Polytechnic Institute and State University, Blacksburg. 
McElroy, M.B. and M.J. Horney (1981): "Nash-Bargained Household Decisions: Toward a Generalization of the Theory of Demand," International Economic Review, 22, 333-350.

McElroy, M.B. and M.J. Horney (1990): "Nash-Bargained Household Decisions: Reply," International Economic Review, 31, 237-242.

Quinzii, M. (1984): "Core and Competitive Equilibria with Indivisibilities", International Journal of Game Theory, 13, 41-60.

Rochford, S.C. (1984): "Symmetrically Pairwise-Bargained Allocations in an Assignment Market", Journal of Economic Theory, 34, 262-281.

Roth, A.E. and M.A.O. Sotomayor (1990): Two-Sided Matching: A Study in Game-Theoretic Modeling and Analysis, Cambridge University Press.

Shapley, L.S. and M. Shubik (1972): "The Assignment Game I: the Core", International Journal of Game Theory, 1, 111-130.

Snyder, S.K. (2000): "Nonparametric Testable Restrictions of Household Behavior," Southern Economic Journal, 67, 171-185.

Snyder, S.K. (1999): "Testable Restrictions of Pareto Optimal Public Good Provision," Journal of Public Economics, 71, 97-119.

Snyder, S.K. (2001): "Observable Implications of Equilibrium Behavior on Finite Data," Department of Economics, Virginia Polytechnic Institute and State University, Blacksburg, VA.

Suen, W. and H.-K. Lui (1999): "A Direct Test of the Efficient Marriage Market Hypothesis", Economic Inquiry, 37, 29-46.

Udry, C. (1996): "Gender, the Theory of Production and the Agricultural Household", Journal of Political Economy, 104, 1010-1046. 